\title{
GASEOUS PHASE COAL SURFACE MODIFICATION FINAL TECHNICAL REPORT
}

\section{JOSEPH M. OKOH, JACK PINION and SUNIT THIENSATIT \\ Department of Natural Sciences, University of Maryland Eastern Shore, Princess Anne, MD.21853.}

Grant No. DE- FG22-88PC88926 US Dept. of Energy

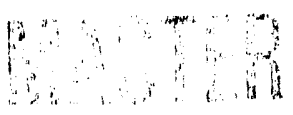




\title{
GASEOUS PHASE COAL SURFACE MODIFICA TION
} FINAL REPORT

\author{
JOSEPH M. OKOH, JACK PINION and SUNIT THIENSATIT \\ Department of Natural Sciences, University of Maryland Eastern Shore, \\ Princess Anne, MD.21853.
}

\section{INTRODUCTION}

The essence of coal preparation is the separation of impurities from coal. The readily identifiable economic benefit factors that derive from buming prepared coal such as i) reduction in slagging and deposition problems in furnaces, ii) providing higher heat content per tonnage of coal, and iii) reduction in the amount of coal handled by power plants, make coal preparation a necessity. The real need is for a coal demineralization process that is feasible, practical, and cost effective. Such a process must reduce the mineral content of coal especially pyrite to below a certain degree, and provide a high BTU recovery with minimal loss of fuel.

One of the ways of achieving the stated objective is by flotation. Froth flotation has proven effective in the cleaning and beneficiation of ultrafine coal. In the U. S., approximately 10 to 15 million tons of coal are cleaned by this technique, based on the inherent hydrophobicity of its carbonaceous matter. Since the response of a coal to flotation is controlled directly by the nature of its external surface, its surface properties and therefore, floatability would vary according to i) the rank of the coal, ii) the content and nature of the active oxygen functional groups, and iii) the inorganic impurities. Next to carbon, oxygen is the most abundant element in coal. Thus oxygen functionality must contribute to its surface chemical behavior much to a greater extent than nitrogen and sulfur. In general, phenolic (-OH) and carboxylic (-COOH) groups are the most important surface oxygen groups. Oxidation of coal surface increases its oxygen functionality. The effect of surface oxidation, which is deleterious to flotation, can be minimized by surface chemical treatment.This method is not new in mineral processing.

H. L. Shergold and C. J. Hartley in their studies of the surface chemistry of diamond noted the possible groups on the surface as: carbonyl, carboxylic, lactone, cross linked oxygen, epoxide and $3^{\circ}$ alcohol. Reaction of these surface functional groups with diazomethane replaced the ionizable hydrogen in the phenol, alcohol and 
carboxylic functionalities with alkyl groups, resulting in the formation of esters and ethers. Methylation of the diamond surface using this procedure increased the advancing contact angle from $25^{\circ}$ to $48^{\circ}$. Since a surface that is completely covered with methyl groups $\left(\mathrm{CH}_{3}\right)$ has an advancing contact angle of $110^{\circ}$, it was suggested that the diamond surface was only partially covered by sites which were susceptible to methylation.

Coal has served as a substrate for many known organic reactions. One such reaction is Friedel-Crafts alkylation. Aromatic compounds which are used as substrates in Friedel-Crafts condensations include phenols and aryl ethers. Such compounds have been known to exist in coal, and have been alkylated. Alkylation using aluminum chloride $\left(\mathrm{AlCl}_{3}\right)$ with alkyl chlorides and olefins, has been reported. Also high-vitrinite coals alkylate readily with isopropyl chloride. Using aluminurn chloride as catalyst, five alkyl groups have been added per 100 carbon atoms. D. D. Denson and D. W. Bankhouse, have also alkylated coal with ethene, propene and isobutene using anhydrous hydrogen fluoride at $135^{\circ} \mathrm{C}$ and moderate pressures. With propylene, up to 18 alkyl groups were added per 100 carbon atoms. Liotta has selectively $O$ methylated lower rank subbituminous and bituminous coals with reactive hydroxylic and carboxylic acid groups. The method developed by Liotta enables the exclusive alkylation of the weakly acidic phenolic and carboxylic acid groups in bituminous and sub-bituminous coals to form the corresponding methyl ethers and esters. This procedure selectively caps the acidic hydroxyls. The NMR spectra of alkylated coal have been evaluated. Calculations based on the uptake of isobutene, the alkylating agent, indicate that $80-90 \%$ of the aromatic protons remained unreacted during the reaction. Consequently, it was concluded that surface alkylation occurred, with only the aromatic hydrogens at the coal surface undergoing substitutions. When the alkylated coal was solubilized, the solution contained micro particles whose surfaces were fully alkylated.

In this report, we present an improved, feasible and potentially cost effective method of cleaning and beneficiating ultrafine coal. Increased mechanization of mining methods and the need towards depyritization, and demineralization have led to an increase in the quantity of coal fines generated in recent times. For example, the 
amount of -100 mesh coal occurring in coal preparation plant feeds now typically varies from 5 to $25 \%$ of the total feed. Environmental constraints coupled with the greatly increased cost of coal have made it increasingly important to recover more of these fines. Our method chemically modifies the surface of such coals by a series of gaseous phase treatments employing Friedel-Crafts reactions. By using olefins (ethene, propene and butene) and hydrogen chloride catalyst at elevated temperature, the surface hydrophobicity of coal is enhanced. This increased hydrophobicity is manifest in surface phenomena which reflect conditions at the solid/iquid interphase (zeta potential) and those which reflect conditions at the solid/iquid/gas interphases (contact angle, wettability and floatability).

\section{EXPERIMENTAL}

\section{Gaseous Phase Alkylation:}

The coal sample that was used was Illinois $\# 6$, pulverized to a mesh size of $100 \times 325$. Common chemicals such as methyl isobutyl carbinol, hydrogen chloride gas, and olefins such as ethene, propene and butene were used as received.The reactor system is shown in Figure 1. The reaction occurred in the gas phase. Twenty grams of pulverized coal were loaded into the reactor and nitrogen gas was fed through a rotometer into the rector system for 10 minutes at room temperature. Next the temperature of the furnace was increased to the optimum reaction ternperature of $182^{\circ} \mathrm{C}$ and the system flushed further for 10 minutes with nitrogen.

The nitrogen gas was turned off and the reactant gases, $\mathrm{HCl}$ and ethene in mole ratio of $1: 33$ were fed through the rotometer into the system at $182^{\circ} \mathrm{C}$ for 90 minutes.During the reaction, the effluent waste gases were absorbed in water and scrubbed with $10 \mathrm{M} \mathrm{NaOH}$. At the end of reaction, the reactant gases were turned off and the reactor system was flushed with nitrogen until its contents returned to room temperature. The coal sample thus treated was collected and stored at room temperature. The above procedure was repeated by passing propene and butene respectively with hydrogen chloride in the same molar ratios as above , over fresh 20.0 $\mathrm{gm}$. batches of untreated Ill. \#6 . 


\section{Characterization of Coal Surfaces:}

\section{Diffuse Reflectance IR Fourier Transform (DRIFT):}

The coal samples utilized were treated and untreated Illinois $\# 6$. The DR equipment

consisted of a model DRA-SID accessory. The spectra were scanned at $2 \mathrm{~cm}^{-1}$ resolution on a digilab FTS-15C Fourier Transform Infrared Spectrometer at the signal average of 100 interferograms. Immediately prior to and during the course of the measurements, the instrument and samples were purged with high purity nitrogen. Duplicate runs were made.

\section{Photoacoustic FTIR Analysis:}

All spectra were obtained on a Mattson Polaris FTIR spectrometer using ICON software provided by the manufacturer. Detection of the photoacoustic signal was achieved with a helium purged MTEC model 100 photoacoustic cell. Each spectrum was ratioed against a carbon black background ( Norit - A ). Spectra were obtained with a resolution of $8 \mathrm{~cm}^{-1}$. Mirror velocity and number of scans are provided in the caption of each spectrum.Spectral comparisons were made at identical mirror velocities. Comfarison of peak height or area was relative.

\section{Electrokinetic Measurements:}

A Laser Zee Model 500 zeta meter was used for the zeta potential measurements of both treated and untreated coal saniples.In all cases, the zeta potentials were measured using potassium nitrate as the supporting electrolyte, and the $\mathrm{pH}$ was adjusted by the addition of $\mathrm{HNO}_{3}$ or $\mathrm{NaOH}$.

\section{Extraction Of Coal:}

Ground coal samples (treated/untreated) were used. A 50/50 (by volume) mixture of chloroform and ethyl acetate was prepared. 1 gram of coal sample and $20 \mathrm{ml}$. of the above solution were mixed and stirred for ten minutes at room temperature. The mixture was filtered through \# 42 filter paper. The absorbance of the filtrate was read as is on a uv/vis. spectrophotometer at $400 \mathrm{nrn}$.

\section{Oxygen Functional Group Analysis:}

The carboxylic groups in the coal samples were determined by refluxing $125 \mathrm{mg}$. of coal in air with calcium acetate $(0.1 \mathrm{~N}$ solution, $50.0 \mathrm{mls}$, $\mathrm{pH}=8.25$ ) for four hours and potentiometrically titrating the released acid under nitrczen with alkali $(0.05 \mathrm{~N})$ until the $\mathrm{pH}$ value of 8.25 was restored. A glass- calomel electrode combinatior. 
served as the measuring device. The total acidity of the coal sample was determined by reacting the coal with excess barium at high $\mathrm{pH}$, namely with a solution of $0.2 \mathrm{~N}$ barium hydroxide plus $0.8 \mathrm{~N}$ barium chloride under nitrogen. After treatment, the excess barium hydroxide was determined by backtitration with $0.1 \mathrm{~N} \mathrm{HCl}$. The concentration of the phenolic groups was obtained by subtracting the concentration of the carboxylic functionality from the total acidity.

\section{Wettability}

Approximately 3.00 gram: of coal powder that was treated as described above and the untreated variety respectively, were loaded into a glass tube with a fritted end. The tube was always very carefully filled to the same height by tapping over two hundred times. The packed tube was placed in a wetting liquid, and the wetting height was measured as a function of time. From such measurement and by the use of Washburn's equation, the packing constant was calculated from the slope of a graph of the square of the wetting height in meters against time in seconds. By using the calculated packing constant the contact angles of treated and untreated powdered coal samples were calculated. When the $\mathrm{pH}$ of the wetting liquid was varied, the equilibrium $\mathrm{pH}$ of the resulting coal slurry rather than the wetting liquid was measured.

\section{Density/elemental analysis}

The density and elemental analysis data were provided by Micromeritics, Inc. One Micromeritics Drive, Norcross, GA 30093-1877.

\section{Floatability}

One gram of treated or untreated coal was added to $60 \mathrm{~mL}$ of deionized-distilled water. After one minute of mixing, methyl isobutyl carbinol (MIBC) was added as a frothercollector at a dosage of $0.015 \mathrm{Kg} / \mathrm{mt}$. The slurry was stirred for one minute and air was introduced for flotation. Airflow rate was maintained constant for different flotation experiments by the us of a rotometer. Coal froth was collected for three minutes at most, dried to a constant weight with an infrared lamp, and weighed.

\section{RESULTS AND DISCUSSION.}

Extraction studies: Measurement of UV absorbance of chloroform-ethanol extracts produced during brief exposure of coal at room temperature to extraction solvents is a measure of the degree of surface modification. We extracted samples of untreated I11. it 6 coal with the above solvent system, and measured the absorbance of the extraction solvent at $400 \mathrm{~nm}$. Extractable $\mathrm{U}^{\prime}$ absorbing material and hydrophobicity as measured 
by contact angle, etc. are measures of surface modification. Extraction of butene treated coal gave the highest readings (Table I), although it did not give the greatest recovery during flotation. Polyalkenes formed on the particle surface or surface alkylation are both probably responsible for the behavior.

Density measurement: Data for untreated coal, and for coal modified by gas phase alkene treatment are given in Table II. Untreated coal has the highest density, followed in decreasing order by ethene, butene, and propene treated samples. Modification of coal by surface alkylation would be expected to change its secondary structure, since there is a decrease in polarity of adjacent surfaces which are held together by electrical forces within pores of the coal particles. These changes would cause swelling and increase of particle volume during nitrogen gas density determinations.

Elemental analysis data: Analytical data for samples of 111 \#6 coal treated with $\mathrm{HCl}$ and various alkenes is given in table III. Carbon/hydrogen ratios show an expected change with alkylation compared to untreated samples. Between both, the sample which was treated with nitrogen gas and $\mathrm{HCl}$ has higher carbon and hydrogen and lower moisture and ash content. The reaction of acid with the $\mathrm{CaCO}_{3}$ present in the mineral part of the coal causes loss of both moisture and $\mathrm{CO}_{2}$. The weight of the sample, when corrected for this acid reaction, correlates density data with other measures of hydrophobicity.

Mechanism of Alkylation: The process of Friedel-Crafts alkylation in the gas phase using anhydrous $\mathrm{HCl}$ probably involves a mechanism which is the reverse of that proposed for removal of alkyl groups from ethers and esters as alkyl halides. Such a process would include acid catalyzed formation of alkyl cations which react with unshared electron pairs on oxygenated functional groups. The products of these reactions are oxonium ions which may lose protons and become ethers (from phenols) and alkylated ester (from carboxylic acids). These reactions are illustrated in fig. 12. Covalent bonds may be made between alkyl functional groups and oxygen (hydrophobic) to replace acidic hydrogen-oxygen bonds (hydrophilic). These are observed in the DRIFT and PA-FTIR spectra of coal which has been treated with alkenes and $\mathrm{HCl}$ in the gase phase at $180^{\circ} \mathrm{C}$.

Extration studies show that this type of surface alkylation my represent only a part of the modification which increases the recovey of fine coal particles during froth floation. This is because there is a part of the "alkylation" which may be superficial coating of polymer. The coal substrate may act as a catalyst and support for this further reaction. 
FTIR SPECTRA : In order to determine the change in hydrogen bonded oxygen absorption with alkylation , DRIFT spectra were determined for treated and untreated III \#6 coal samples . Results are presented in figures 2 through 8. Significant changes in the infrared difference spectra observed before and after treatment show that $\mathbf{O}$-alkyl bonds have replaced $\mathrm{O}-\mathrm{H}$ bonds.

In figure 2 , (spectrum of untreated Ill\#6) a broad unresolved band, due to $\mathrm{OH}$ stretch from 3300 to $3600 \mathrm{~cm}^{-1}$ is apparent. Alcoholic, phenolic and acidic - OH groups absorb in this region. The band at ca. $3050 \mathrm{~cm}^{-1}$ is due to the carbon hydrogen stretch vibrations within the aromatic structures of the coal. The sharp peak from 2800 to $3000 \mathrm{~cm}^{-1}$ is characteristic of alkyl C-H due to ester, ether and non oxygen bound alkyl groups. A small but prominent band at ca. $2730 \mathrm{~cm}^{-1}$ due to $\mathrm{CH}$ stretch vibrations of the aldehyde components of the coal is also noted. Carbonyl bands resulting from various modes range from $1665-1700 \mathrm{~cm}^{-1}$ depending on the degree of oxidation of the surfaces of the coal particles. This particular absorption, due to unesterified carboxylic acids is obscured by the aromatic $\mathrm{CH}$ band near $1600 \mathrm{~cm}^{-1} \mathrm{~A}$ strong band at ca. $1605 \mathrm{~cm}^{-1}$, universally found for polynuclear aromatic hydrocarbons is also pronounced. The band at ca. $1450 \mathrm{~cm}^{-1}$ is associated with the bending mode of vibration of aliphatic hydrocarbons. At first glance, the spectra of the untreated IIl. \#6 (fig. 2), does not seem to be very different from that of the treated samples figs. $(3-5)$. However, the chemical information is forthcoming in the difference spectra calculated by computer aided processing of the 2300 data points of each spectrum ( figs. 6-8). In these spectra, any excess in the concentration of a chemical species, especially in the treated coal over that of the original untreated sample, is noted as a positive band, ie above the zero horizontal line. Conversely, the negative bands for hydroxyls ( carboxylic, alcoholic and phenolic ) carbonyls and aldehyde show that generally the untreated coal contained more surface hydrophilic functionalities than the treated coal samples. These negative bands appear from ca. $2600-3600 \mathrm{~cm}^{-1}$ ( hydroxyl groups ) and $1780-1905 \mathrm{~cm}^{-1}$ (carbonyl groups). From the foregoing, one can infer that the absorption due to oxygen bound hydrogen decreases while the oxygen bound carbon absorption increases due to the replacement of oxygen bonded hydrogen atoms by alkyl groups as a result of the gaseous treatment. 
The spectrum of newly exposed surface of treated III \#6 as a result of grinding and its difference spectrum with that of the treated simple which is not subjected to further grinding are presented in figures 9 and 10 . The newly exposed surface appears to be enriched with virtually every functional group and mineral component , as evidenced in positive features. Two inferences can be drawn from this latter observation: i) Chemical modification occurs on the coal surface.ii) As a result of gaseous phase treatment, the hydrophilic functionalities of treated coal decrease, while the hydrophobic increase. This alters the coal hydrophobic/hydrophilic balance in favor of hydrophobicity.

These results are corroborated by the observations from comparative Photoacoustic FTIR analysis. If one considers the area covere! by the broad triangular shaped band arising from the hydrogen bonded hydroxyl stretches within the am ( rphous coal matrix, (ca. $\left.3600-2500 \mathrm{~cm}^{-1}\right)$ there is a progressive decrease in magnitude in the order : untreated coal > propene > butene treated samples (figs.11 13). This order is indicative of a progressive increase in coal surface hydrophobicity from untreated coal through the butene treated variety.

\section{OXYGEN FUNCTIONAL GROUP ANALYSIS}

Surface enhanced hydrophobicity is also demonstrated in oxygen functional group analysis. Using the calcium acetate method, the acidity of untreated Ill.\#6 was computed to be 2.00 meq. $\mathrm{H}^{+} / \mathrm{g}$. The nitrogen treated Ill. \#6 had acidity of 1.20 meq. $\mathrm{H}^{+} / \mathrm{g}$. Olefin (ethene, propene and butene) treated Ill\#6 generally had $0.00 \mathrm{meq} \mathrm{H}^{+} / \mathrm{g}$ acidity. Using the barium hydroxide method, the quantity of standard acid that was needed to back titrate excess base is presented in table IV. From the back titration, the total acidity of the coal samples viz. untreated, and nitrogen, ethene, propene and butene treated samples were computed. Results are also presented in table IV.

The results clearly demonstrate reluced surface acidity (carboxylic plus phenolic) as a result of gaseous phase treatment. Coal surface hydrophobicity tends to be inversely related to an increase in the content of the carboxylic and phenolic groups in coal. Carboxylic groups exert their effect through ionization in aqueous solution, thereby affecting the magnitude of the electric charge on the coal surface. Apart from the former, the hydrogen atoms of both the phenolic and carboxylic functionalities may attract water molecules to the coal surface via hydrogen bonding.In addition, the double bonds associated with the carbonyl groups have a strong polar character, and they can attract polar water molecules to the coal surface, rendering it hydrophilic. 


\section{Extraction of Coal:}

The degree of superficial extractability of coal shows a good correlation with flotation results. Also a strong correlation exists between coal carbon content, contact angle and floatability. Spitzer in "effects of coal surface properties on processing", observed a linear relationship between the absorbance of superficial coal extract and floatability. These observations are consistent with absorbance, being a direct measure of the concentration of the hydrophobic groups on coal surface.

The results of the superficial extraction studies, using treated/untreated coals, are presented in table $I$. The trend potrays increased coal surface hydrophobicity as a result of gaseous phase treatment. The absorbance of the superficially extracted butene treated sample was the highest $(0.553)$. Least absorbance was recorded for the untreated variety ( 0.221$)$, while the extracts from ethene and propene treated coal samples recorded 0.417 and 0.299 respectively. These observations are indicative of increase in the incidence of alkyl groups on coal surface as a result of gaseous phase treatment and the selective capping off of the hydrophilic functionalities by the same.They support increased surface hydrophobicity in the order : butene treated > ethene > propene > untreated IIl. \#6 samples.

Based on the foregoing and results from FTIR , PA - FTIR studies, and oxygen functional group analysis, the mechanism for alkylation is presented in scheme 1.

Electrokinetic Studies Through the study of electrical effects, surface phenomena which reflect the conditions at the solid - liquid interface such as adsorption density and zeta potential can be correlated directly with surface phenomena like contact angle and froth flotation that reflect conditions at the solid- liquid-gas interface. Using ethene treated coal sample for example, the zeta potential reflects a decrease in the concentration of acidic surface sites compared to untreated coal. Ths zeta potentials in aqueous solution ( $\mathrm{pH} 2.0$ to 10.0 ) of the ethene treated and untreated Ill \#6 coals are presented in figure 14 . Their comparison reveals that: i) the zeta potential of the untreated coal is more negative up to $\mathrm{pH} \sim 6.0$ than that of the treated variety. ii) the curve of the zeta potentials of the treated coal exhibits an isoelectric point at pH 3.3, while the untreated does not. These trends can be explained via adsorption and or ionization. The untreated coal surface consits of phenolic $(\mathrm{pKa}=10)$, carboxylic ( $\mathrm{pKa}$ $=4-5$ ) and sulfonic acid ( $\mathrm{pKa}=1-2)$ functionalities. Increasing $\mathrm{pH}$ will lead to deprotonation, in addition to adsorption, causing the coal surface to acquire negative potential from $\mathrm{pH} 2.0$ to 10.0 . The response of treated coal to $\mathrm{pH}$ changes is quire 
different. As a result of gaseous phase reaction, the phenolic functionalities are converted to ether functional groups, while the carboxylic and sulfonic acids are converted to esters.From $\mathrm{pH} 2.0$ to 3.3, the ether and ester groups become protonated at their oxygen atoms, confering a positive potential on the coal surface. according to the following scheme :
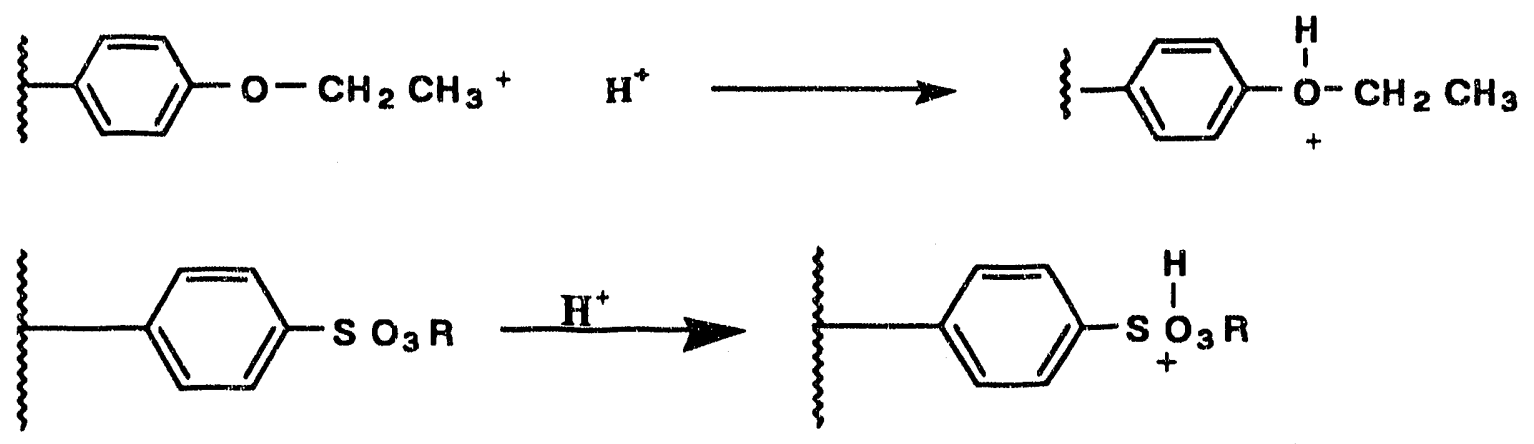

The negative potential ( $\mathrm{pH} 3.3$ to 10.0) may be due to a combination of events such as:

i) partial acid hydrolysis of ester and the subsequent ionization of the carboxylic/sulfonic acid that is formed:

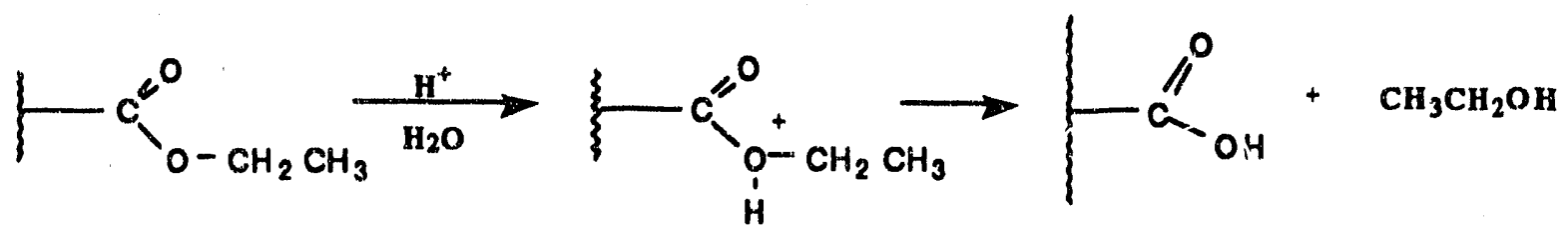<smiles>CC=CC(C)(C)C(=O)[O-]</smiles>

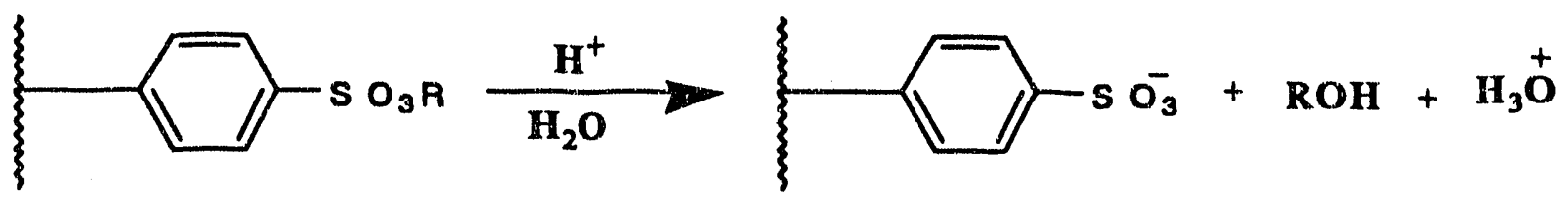
ii) partial alkaline hydrolysis of ester and deprotonation of the carboxylic/sulfonic acid that is formed by $\mathrm{OH}^{-}$:<smiles>CCOC(=O)CCC(=O)CC(C)C(=O)[O-]</smiles> 


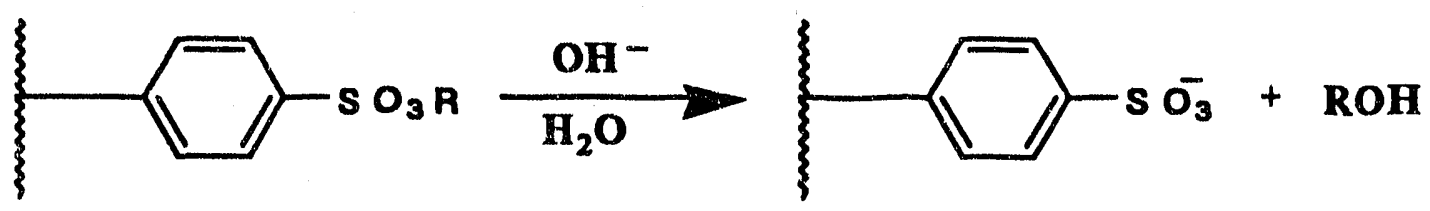

iii) adsorption of $\mathrm{OH}^{-}$directly onto the coal surface.

These equilibrium reactions notwithstanding, the surface of the ethene treated coal is still considerably more hydrophobic compared to the untreated variety, as the polar oxygen/sulfur are no longer terminal, after they have been replaced by alkyl groups.

These observations corroborate other experimental results. Higher absorbance of the superficial extract of treated coal compared to the untreated variety, higher contact angles and floatability and lower work of adhesion between film of water and coal particle are also indicated that alkylation had occured. The contentions above are further supported by the results from DRIFT and Photorcoustic FTIR studies. The reduction in the magnitude of negative surface charge of treated coal compared to the untreated variety indicates reduced surface polarity. This is useful when one considers that in froth flotation of coal, using MIBC as a frother-collector, the adsorption of the latter is of paramount importance.The adsorption occurs mainly through hydrophobic bending via the interaction between MIBC molecules and the hydrocarbon groups on the coal surface. Higher coal surface hydrophobicity or reduced surface polarity facilitates the adsorption process.

\section{Wettability/Floatability}

The wettability of surfaces is of great importance in froth flotation and is commonly studied by contact angle measurements.The wetting and non-wetting properties of a solid can be used as a measure of its hydrophobicity. Wetting means that the contact angle between a liquid and a solid is zero ( the third phase being a gas ). The tendency towards non-wetting approximates contact angles approaching $90^{\circ}$ or higher.

The Dupre equation for wetting : $\cos \theta=\left(\gamma_{\text {sa }}-\gamma_{\text {sl }}\right) / \gamma_{l a}$

where $\gamma_{\text {sa }}=$ Surface tension between solid and air

$\gamma_{\text {sl }}=$ Surface tension between solid and liquid

$\gamma_{\mathbf{b}}=$ Surface tension between liquid and air

$\theta=$ contact angle, 
can be rearranged for a captive bubble that is held onto a coal surface under aqueous environment to yield : $\gamma_{\text {la }} \cos \theta=\gamma_{\text {si }}-\gamma_{\text {sa }}$.

The work of adhesional wetting can then be calculated from :

$$
\mathrm{W}_{\mathrm{A}}=\gamma_{1 \mathrm{a}}(1+\operatorname{Cos} \theta)
$$

By determining the contact angle of coal in a given solution of known surface tension, the work of adhesion may be calculated before and after gaseous phase treatment and compared. The contact angle for powdered coal was determined by the Wasburn equation, since a powder packed in a tube may be considered to consist of a bundle of capillaries of mean radius $\mathrm{Cr}$.

Applying the Washbum equation to a coal powder system yields :

$$
\begin{aligned}
& 1^{2}=[(\mathrm{Cr}) \gamma+\cos \theta] / 2 \eta \\
& \eta=\text { viscosity of the wetting liquid } \\
& t=\text { time in seconds } \\
& \gamma=\text { surface tension of the wetting liquid } \\
& \theta=\text { contact angle }
\end{aligned}
$$

For a given packing of powder , $\mathrm{Cr}$ will be constant. For a typical wetting liquid,

$$
\begin{gathered}
\theta \text { (Contact angle) }=0 \\
\text { If } X=(\gamma t \cos \theta) / 2 \eta \\
1^{2}=(\mathrm{Cr}) X
\end{gathered}
$$

A plot of $\mathrm{l}^{2} \mathrm{Vs} \mathrm{X}$ will yield a slope of $\mathrm{Cr}$ (fig.15). For an essentially non wetting liquid, if

$$
\begin{aligned}
X^{\prime} & =(\gamma t) / 2 \eta \\
1^{2} & =X(C r) \cos \theta . A \text { plot of } 1^{2} V s X^{\circ} \text { will yield a slope of } \mathrm{Cr} \cos \theta \\
\cos \theta & =\text { slope } /(\mathrm{Cr})
\end{aligned}
$$

By applying the above equations, the contact angle of treated and untreated coal samples in water were computed and compared.Successful modification of the surface of Ill \#6 coal was reflected in the results that were obtained from the foregoing wettability studies. These results are presented in figures 15, 16 and table IV.Using 
toluene as the wetting liquid, the wetting rate through the packed bed of capillaries was generally higher for treated coal (butene,ethene and propene treated coals) compared to the untreated variety.The trend was reversed when the wetting liquid was water.Water did not rise in the capillary described by any of the treated coal at pH 7.0. The contact angles of these coals in water were computed to be $90.0^{\circ}$. Even when the $\mathrm{pH}$ of the wetting solutions was varied ( $\mathrm{pH} 1.0-8.0$ ), the contact angles of treated coal remained constant at $90.0^{\circ}$. Results from the same experiment using untreated coal were significantly different. When the $\mathrm{pH}$ of the wetting solution was varied from 1.0 through 8.0 , computed contact angles varied from $33.78^{\circ}$ to $58.88^{\circ}$, with the maximum occurring at $\mathrm{pH} 1.0$ fig.17. Results are presented in table $\mathrm{V}$. Brady and Gauger, have correlated contact angle and hydrophobicity. Horsley and Smith also correlated contact angle and coal rank. Contact angle is an important guide to assessing the floatability of a solid whether the hydrophobicity is induced or natural. Flotation occurs when a finite contact angle is present. Within a mineral collector system, higher contact angles are generally associated with better flotation and hydrophobicity.

The mechanism of particle - bubble attachment can be divided into three stages : (1) particle bubble approach, (2) thinning and rupture of the disjoining film and (3) formation of a stable particle- bubble aggregate capable of withstanding the disruptive turbulence in a flotation cell. The first factor which deals with hydrodynamics will not be addressed here. The second factor will be addressed first. The work of adhesion is a measure of the amount of work that is necessary to rupture the thin film of water which surrounds the coal particle before bubble attachment during flotation. The more hydrophobic the coal particle, the smaller the work of adhesion. The work of adhesion is comprised of dispersion forces $W_{A d}$, hydrogen bonding $W_{A h}$, and electrical forces, $\mathrm{W}_{\mathrm{Ae}}$ The hydrophylic surface has more negative charge than the hydrophobic one, and tends to stabilize the polar film of water which surrounds the coal particle in aqueous medium. As the film thins, the disjoining pressure which acts normal to the film opposing reduction of the film thickness increases to maintain the film in the equilibrium. In the hydrophobic case, the film is rendered unstable due to decreased surface polarity. A decrease in thickness occurs, causing a decrease in the disjoining pressure. This sequence of events conduces a spontaneous rupturing of the film between particle and bubble with increasing hydrophobicity. Such is the situation with 
our surface modified coal.

From the equation : $W_{A}=\gamma_{1 a}(1+\operatorname{Cos} \theta)$, the works of adhesion were calculated to be $71.97 \times 10^{-3}$ and $126.85 \times 10^{-3} \mathrm{Joule} / \mathrm{m}^{2}$ for the ethylene treated and untreated coals respectively.These results illustrate increased coal surface hydrophobicity due to gaseous phase modification.

Although the froth flotation process is generally recognized as the most effective method of cleaning fine coal, it is beset with some difficulties: i) It is inefficient in making good separation with ultrafines. As a result, a large amount of fine coal is often lost to the tailings, causing a reduction in coal company profits and creating environmental problems. ii) About one-third of the recovered coal may have to be expended in driving off moisture from the flotation concentrate. It then becomes uneconomical to carry out an operation that yields effectively slightly more than $50 \%$ of the coal content in the feed (even if it is a high-rank, superficially altered but still hydrophobic coal). iii) High rank coals are easily floated when significant oxidation is absent. However, if coal is oxidized in situ, in storage, in transport or in process, a reduction in its natural hydrophobicity and floatability will result. As the rank of coal is progressively decreased, the effect of its oxidation is greatly intensified. Thus to improve the floatability of heavily oxidized coal fines, new and more effective collector type reagents are needed. Such reagents are yet to be developed and tested. iv) Even when increased flotation is achieved by using increased aeration rate or frother dosage, the rejection of pyrite is diminished. A coal flotation strategy is needed which is fast and which will enhance the difference between the surface properties of pyrite and coal, conducing a higher flotation recovery while depressing pyrite floatability.

The gaseous phase surface modification of coal presents an improved, feasible, cost effective and practical method of circumventing the problems outlined above. Our innovative procedure alkylates the coal surface especially at the phenolic and carboxylic groups via Friedel-Crafts reaction. This alkylation selectively caps the acidic surface hydroxyl groups, restoring hydrophobicity to the surface of oxidized coal and slowing down the rate at which the surface is oxidized.

In the absence of mineral matter, coal surface chemistry is completely controlled by the organic functional groups, especially the oxygen bearing moieties. Even though there are non-ionized carbonyl and aliphatic alcohol groups present, the most important groups, especially in flotation are the ionizable phenolic and carboxylic groups. All of 
these groups contribute to the hydrophilic/hydrophobic balance of sites on the surface and in tum to flotation thermodynamics. By selectively capping the above mentioned functionalities, the coal surface becomes more hydrophobic and enhances coal particle air bubble attachment, as demonstrated in flotation studies, even up to $\mathrm{pH} 11.90$ (figs. 17 and 18). The formation of a stable particle-butble aggregate, capable of withstanding the disruptive turbulence in a flotation cell, is crucial in flotation.

The relationship between the work functions is : $W_{A}=W_{A d}+W_{A h}+W_{A e}$ For hydrophilic surfaces, the tendency of the $\mathrm{W}_{\mathrm{Ae}}$ component is to increase the magnitude of $W_{A}$ in preference to the other two components. However for aqueous coal slurries, especially between particle and air bubble, the contributions of $W_{A d}$ and $W_{A h}$ to $W_{A}$ become more predominant than the contribution from $W_{A e}$ For the surface modified coal, the tendency of both the predominant contributions is to increase $W_{A}$ between coal particle and air bubble via Van der Waal's forces (dispersion forces between surface alkyl groups introduced via alkylation and air bubbles), relative to the untreated or hydrophilic coal. The higher the distribution of hydrophobic/hydrophilic surface sites in favor of increased hydrophobicity , the higher the work of adhesion between coal particle and air bubble. Consequently the coal floats better.

The rate constant for the flotation process may be calculated from the following first order rate equation :

$$
\begin{aligned}
k & =\left(\ln M_{1}-\ln M_{2}\right) /\left(t_{2}-t_{1}\right) \\
k & = \\
& \text { rate constant, } \min ^{-1} \\
t_{1}, t_{2}= & \text { time in minutes } \\
M_{1}, M_{2}= & \text { weight or distribution percent of a constituent left in the cell at } \\
& \text { time } t_{1} \text { and } t_{2} \text { respectively. }
\end{aligned}
$$

The rate constants for the flotation of coal and of ash rejection are presented in table VI. Higher flotation rates are evident for treated coal, compared to the untreated sample ( fig 19 ). The rate constant, $\mathrm{k}_{\text {coal }}$, for the latter is $0.047 \mathrm{~min}^{-1}$, compared to 0.296 , 0.315 and $0.558 \mathrm{~min}^{-1}$ for the ethene, propene and butene treated samples respectively. In addition to the above, higher ash rejection rates are reported for the treated sampies, compared to the untreated coal. The rate of ash rejection for the latter is $0.017 \mathrm{~min}^{-1}$. The corresponding rates are $0.144,0.150$ and $0.250 \mathrm{~min}^{-1}$, for the ethene, propene 
and butene modified coals respectively. Most spectacularly, the butene treated sample rejected ash 14.7 times better than the untreated coal.

\section{CONCLUSION}

A new coal beneficiation process has been developed which enhances its surface hydrophobicity. Oxidized coal, contains various oxygen functional groups which are hydrophilic in nature. The hydrophilic character was altered substantially under rather mild conditions with $\mathrm{HCl}$ catalyst used during alkylation. This process enhanced coal surface hydrophobicity as the added surface alkyl groups improved flotation kinetics through film thinning phenomena a $\mathrm{d}$ control of the hydrophobic/hydrophilic distribution of surface sites. The coal also de-ashed more efficiently.However, it was not possible to estimate the level of alkylation each type of alkene was able to achieve, or the degree of surface vs. internal reaction,

\section{Acknowledgements}

Financial assistance from Grant No. DE- FG22-88PC88926 from the US Dept. of Energy UCR Program is gratefully acknowledged.

We extend our appreciations to Dr. E. L. Fuller, M\&C, Oak Ridge National Laboratory, Oak Ridge Tennessee and Dr. R. Pfifer of the Ballistic Research Laboratory, Aberdeen Proving Grounds, Aberdeen MD., for the DRIFFT and PA spectra respectively. We thank Dr's Kenneth Jones, Ralph Lai, and MacMahan Gray of the coal preparation division, Pittsburgh Energy and Technology Center, Pittsburgh Pensylvania for useful comments in this manuscript. 


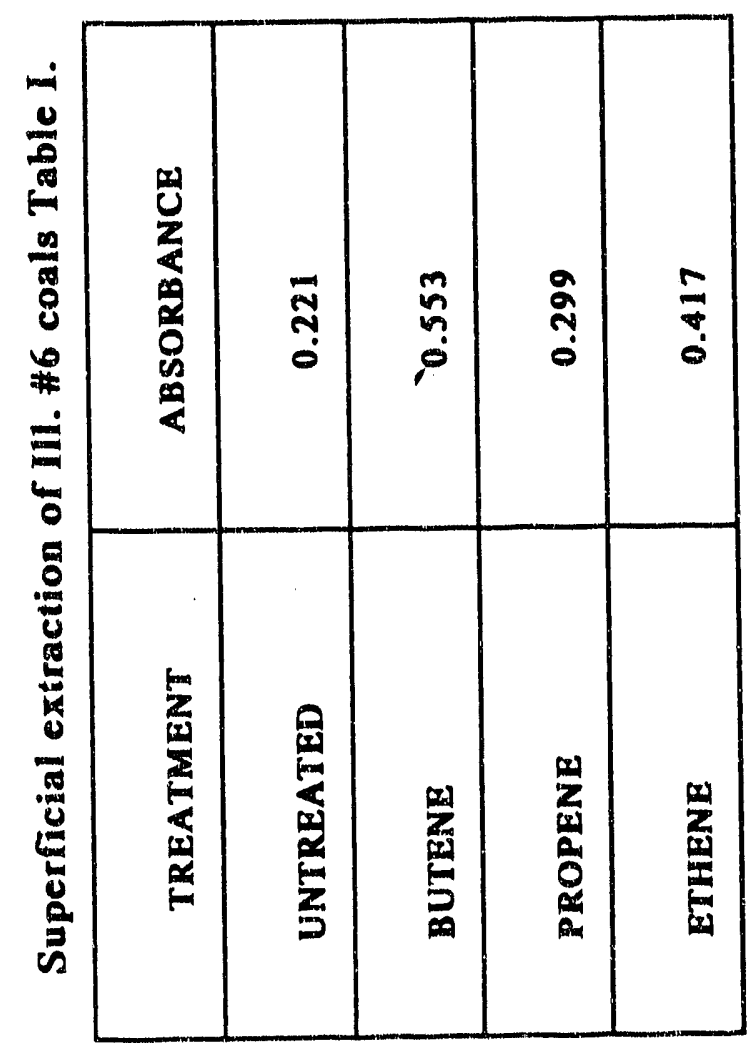




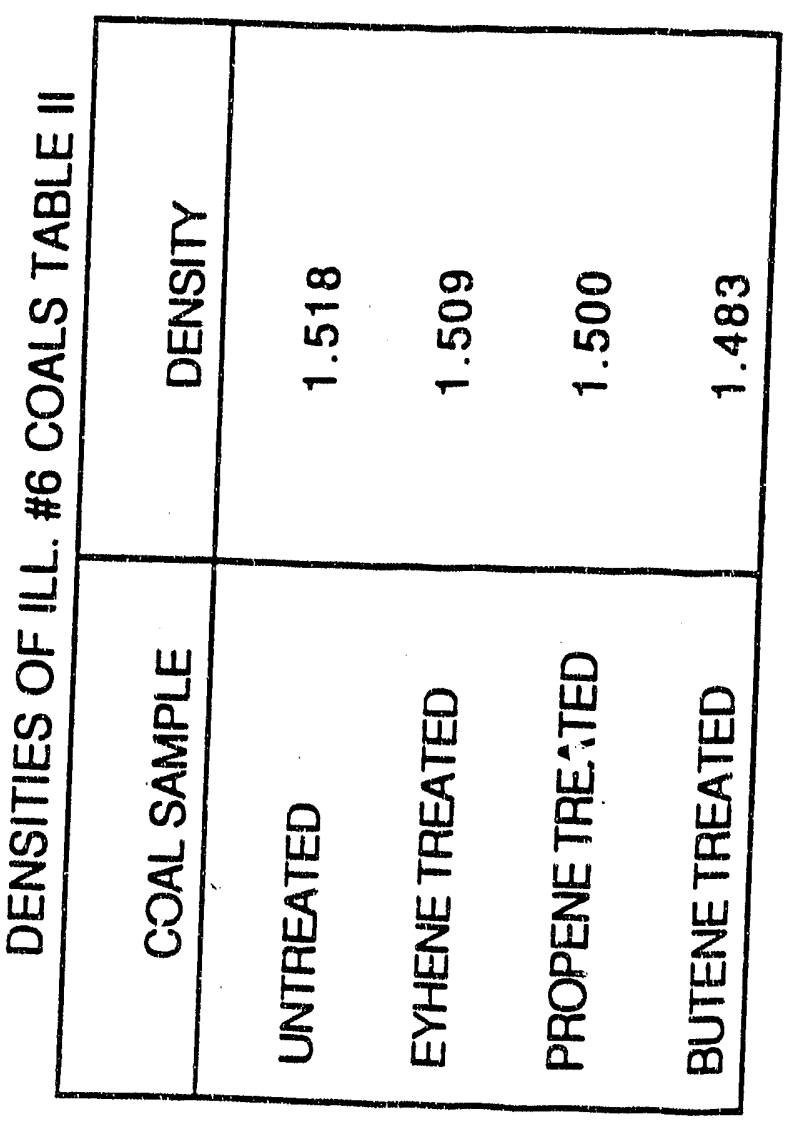




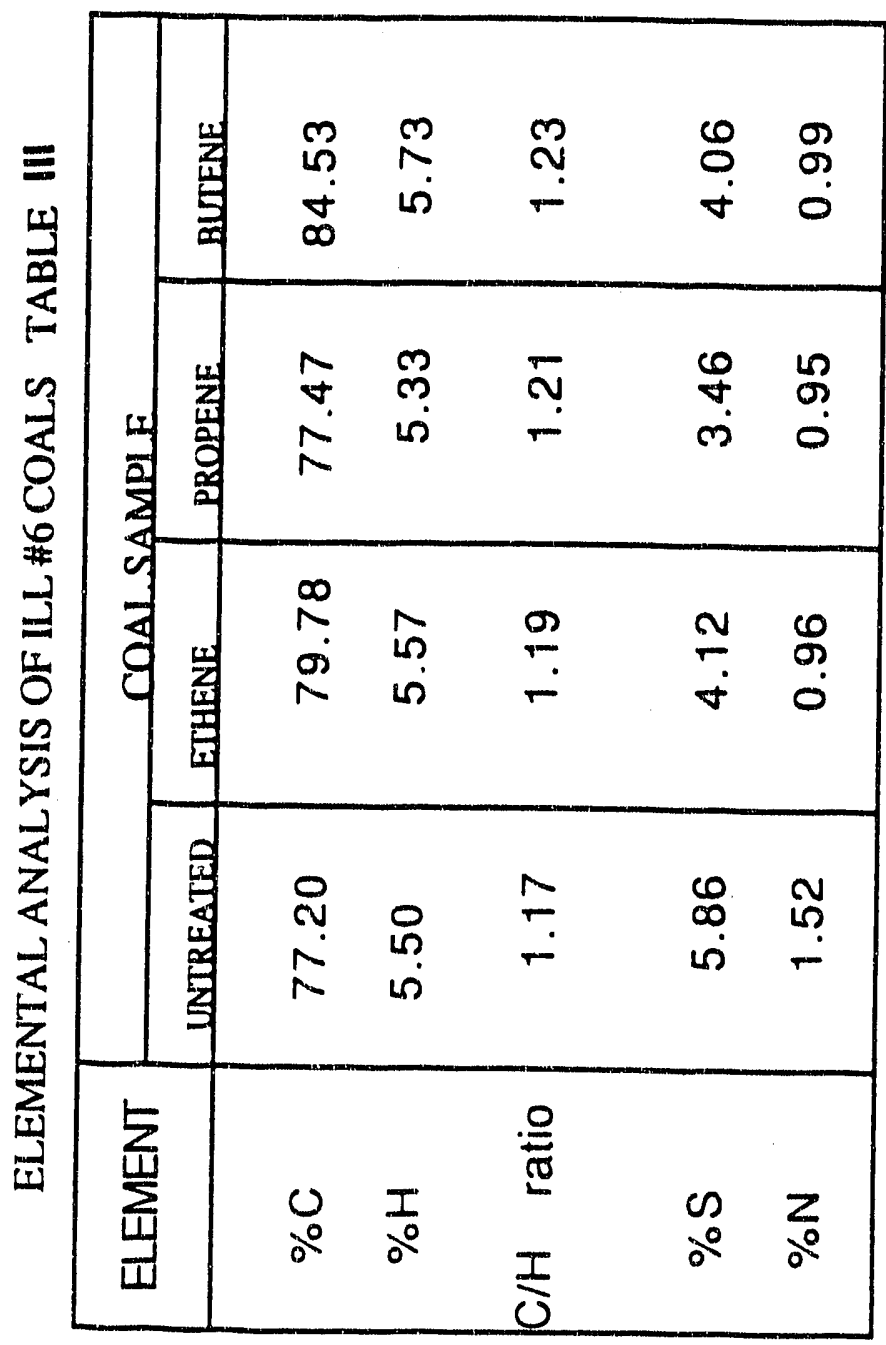




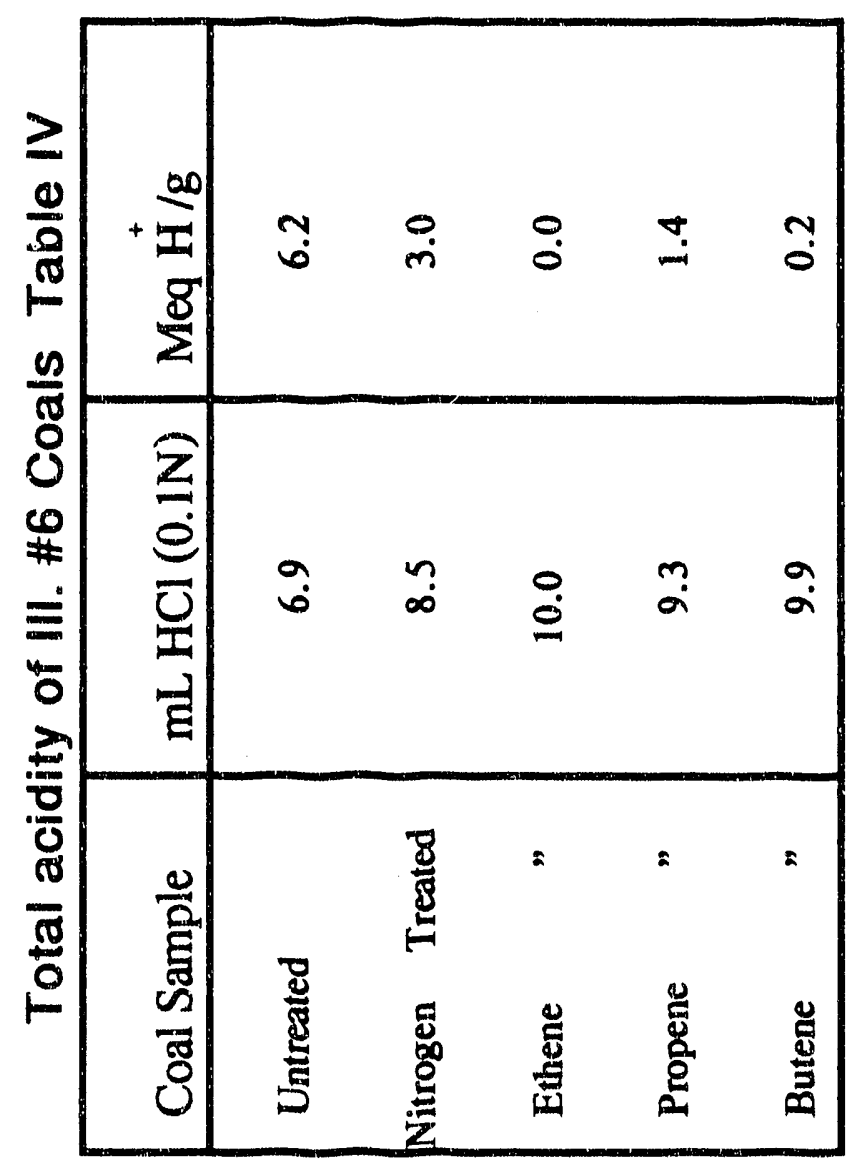




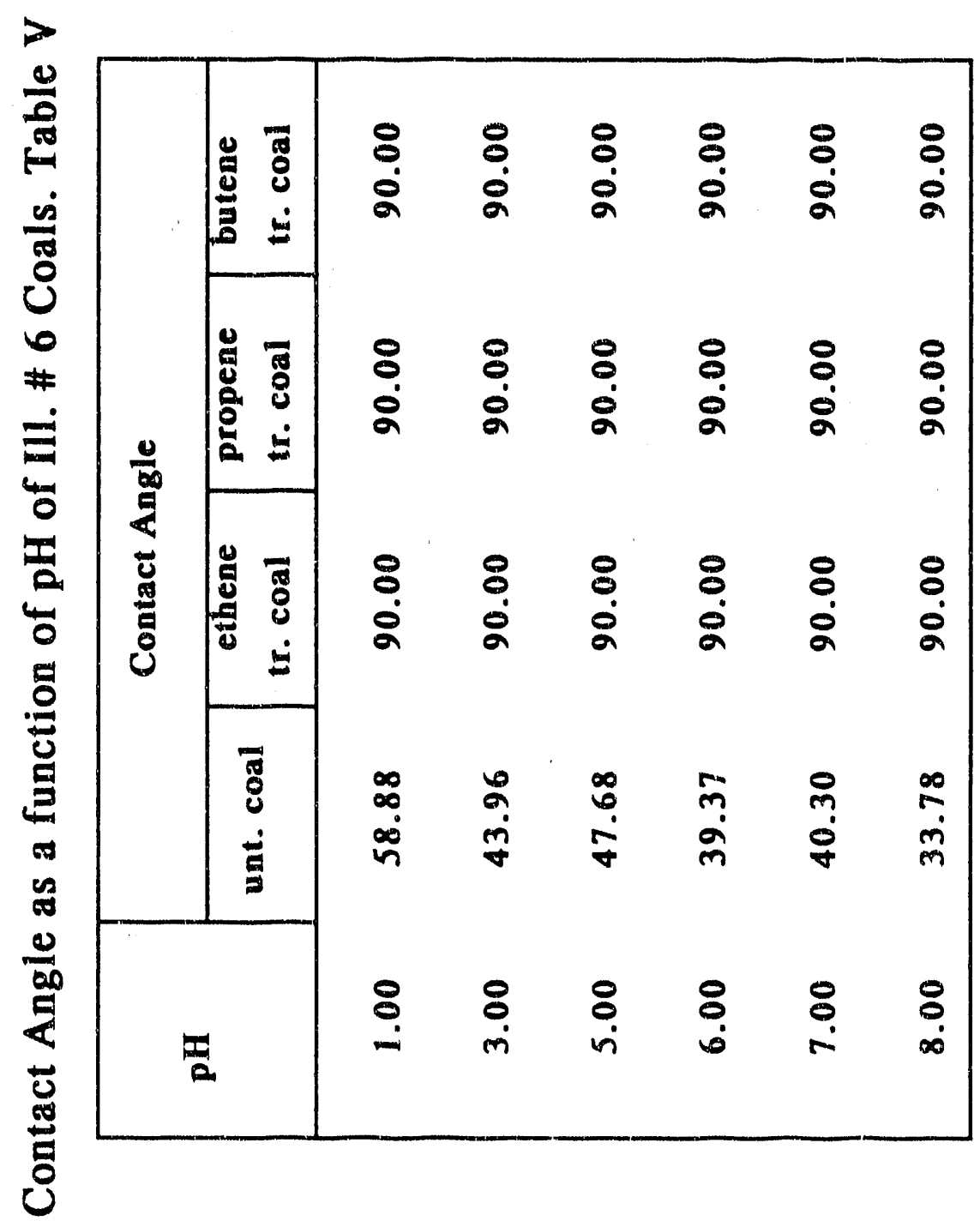




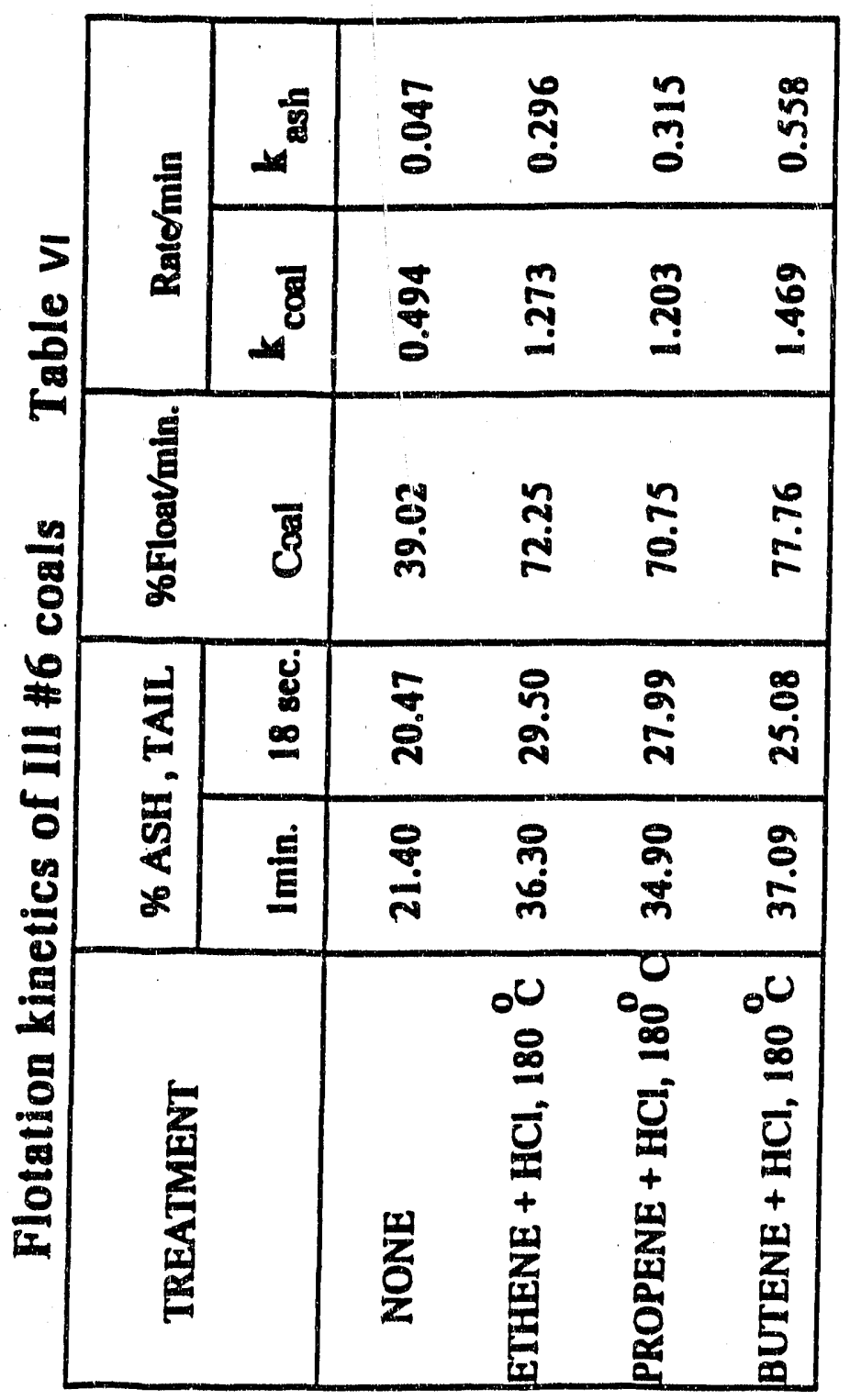




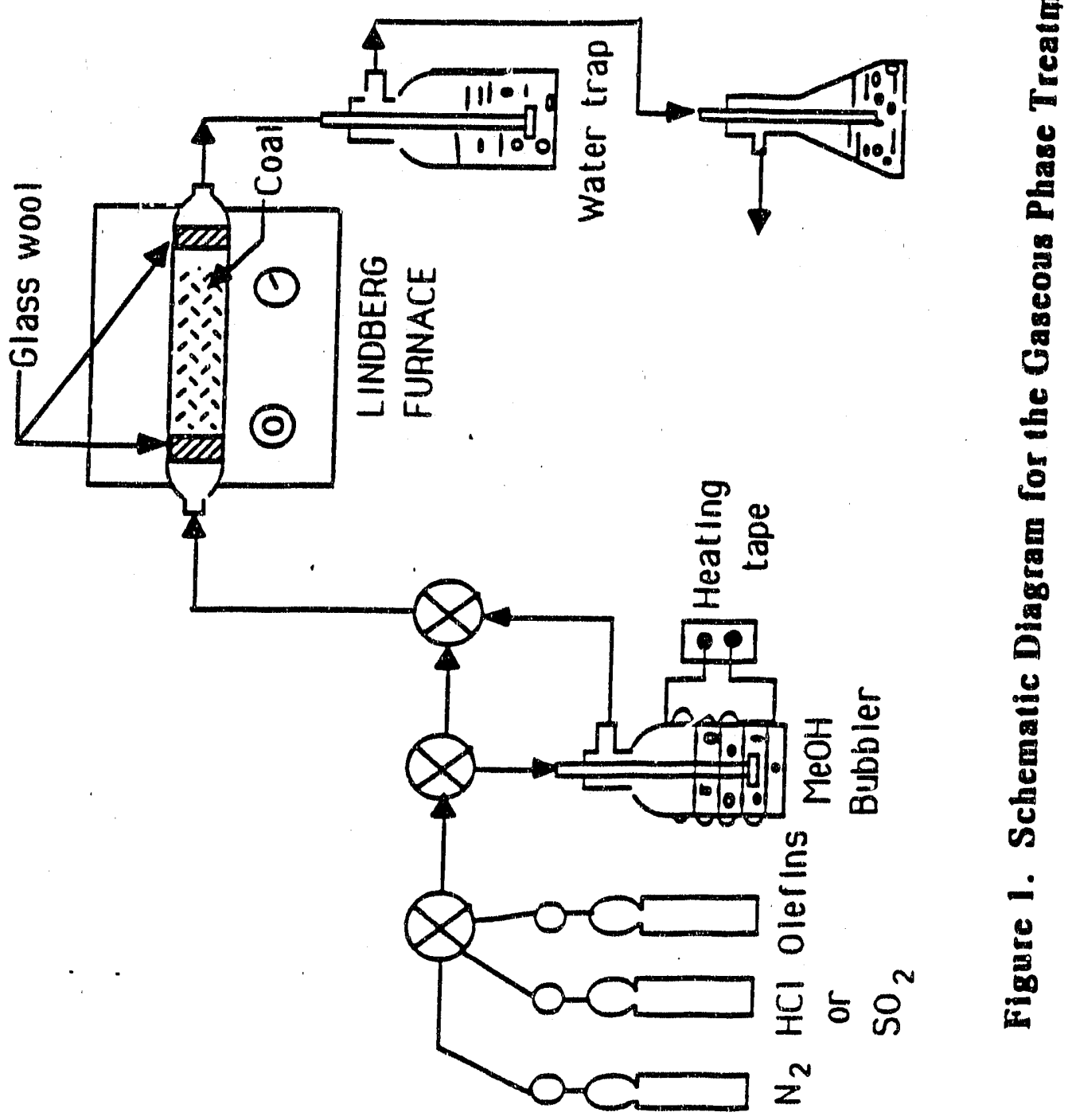




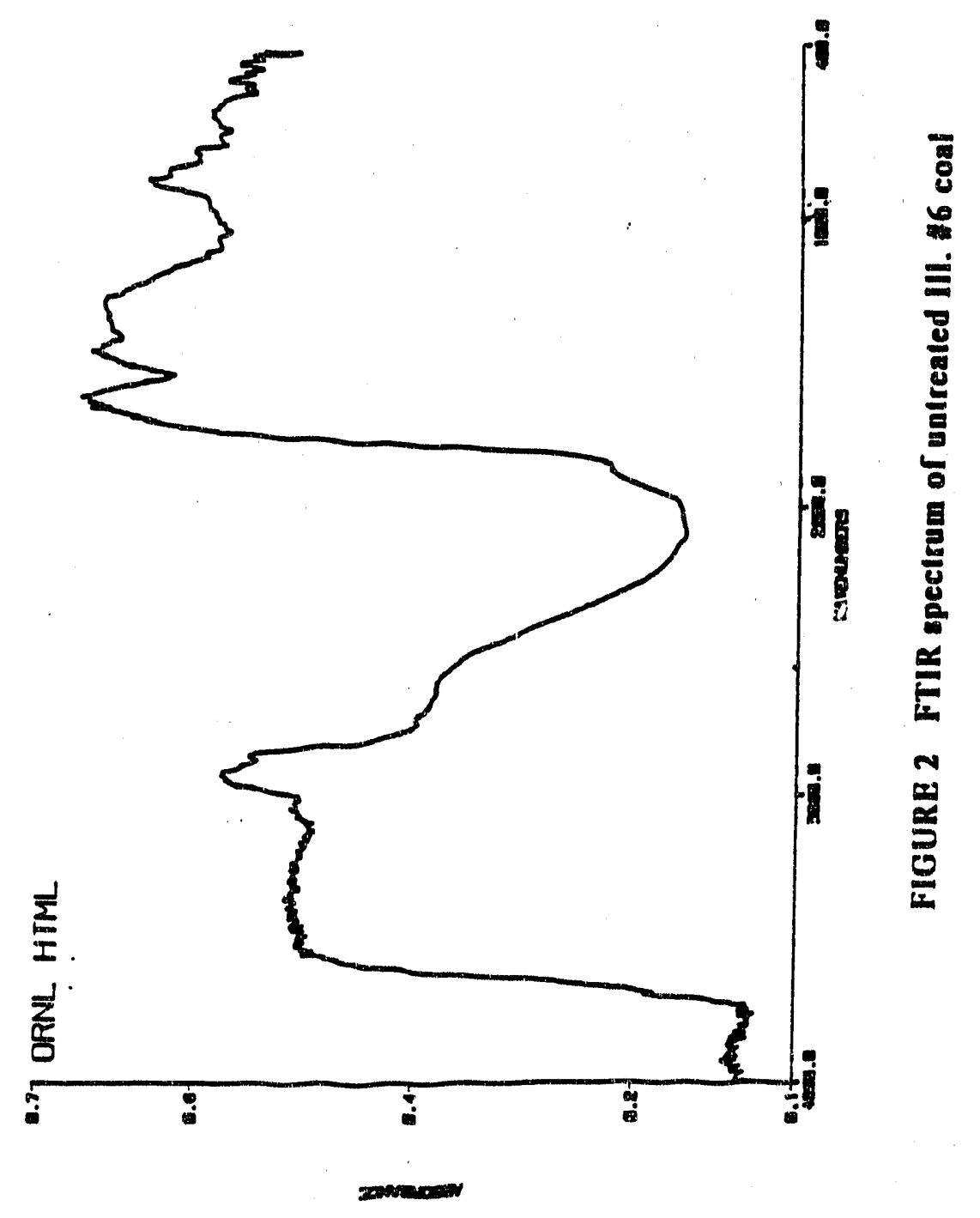




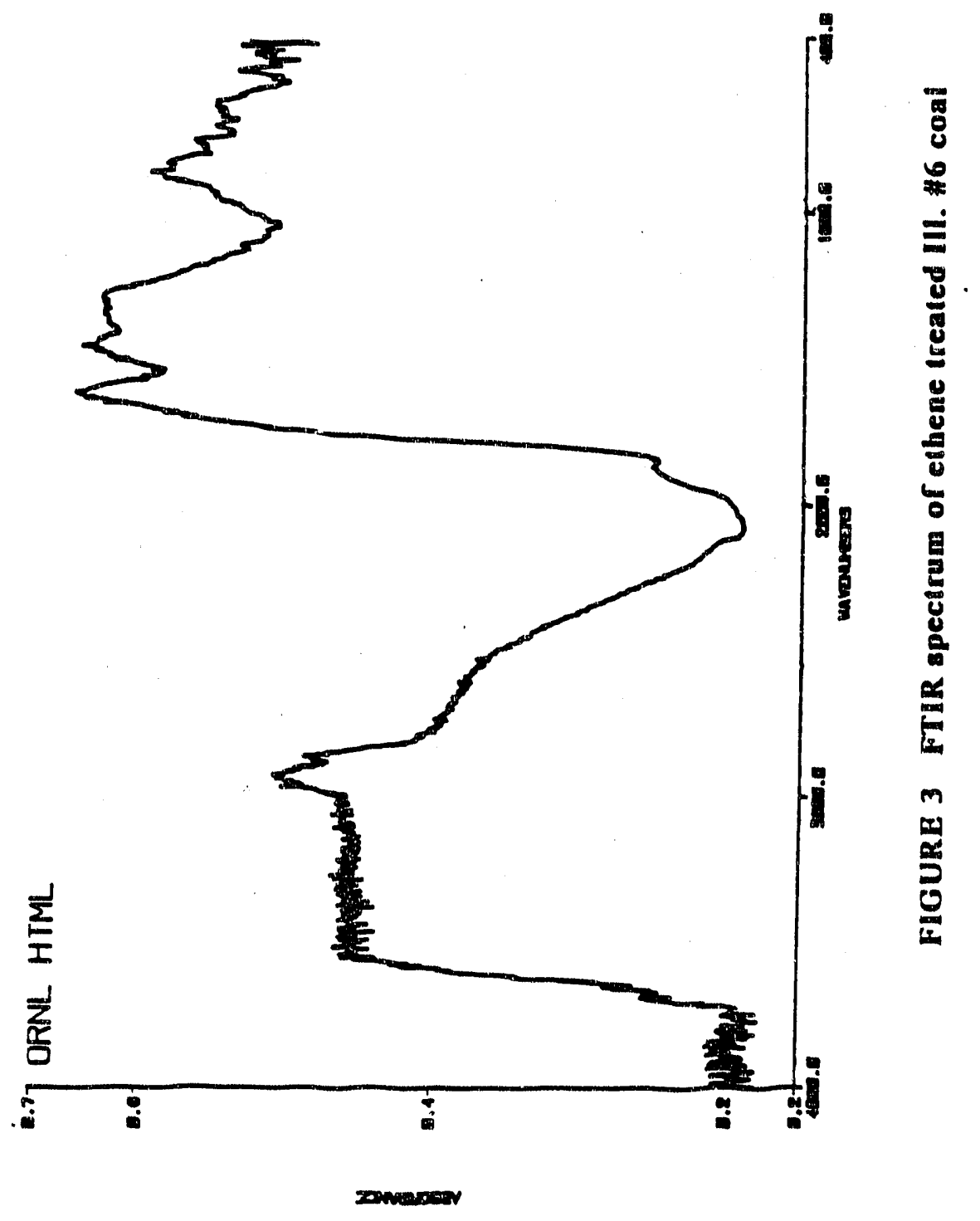




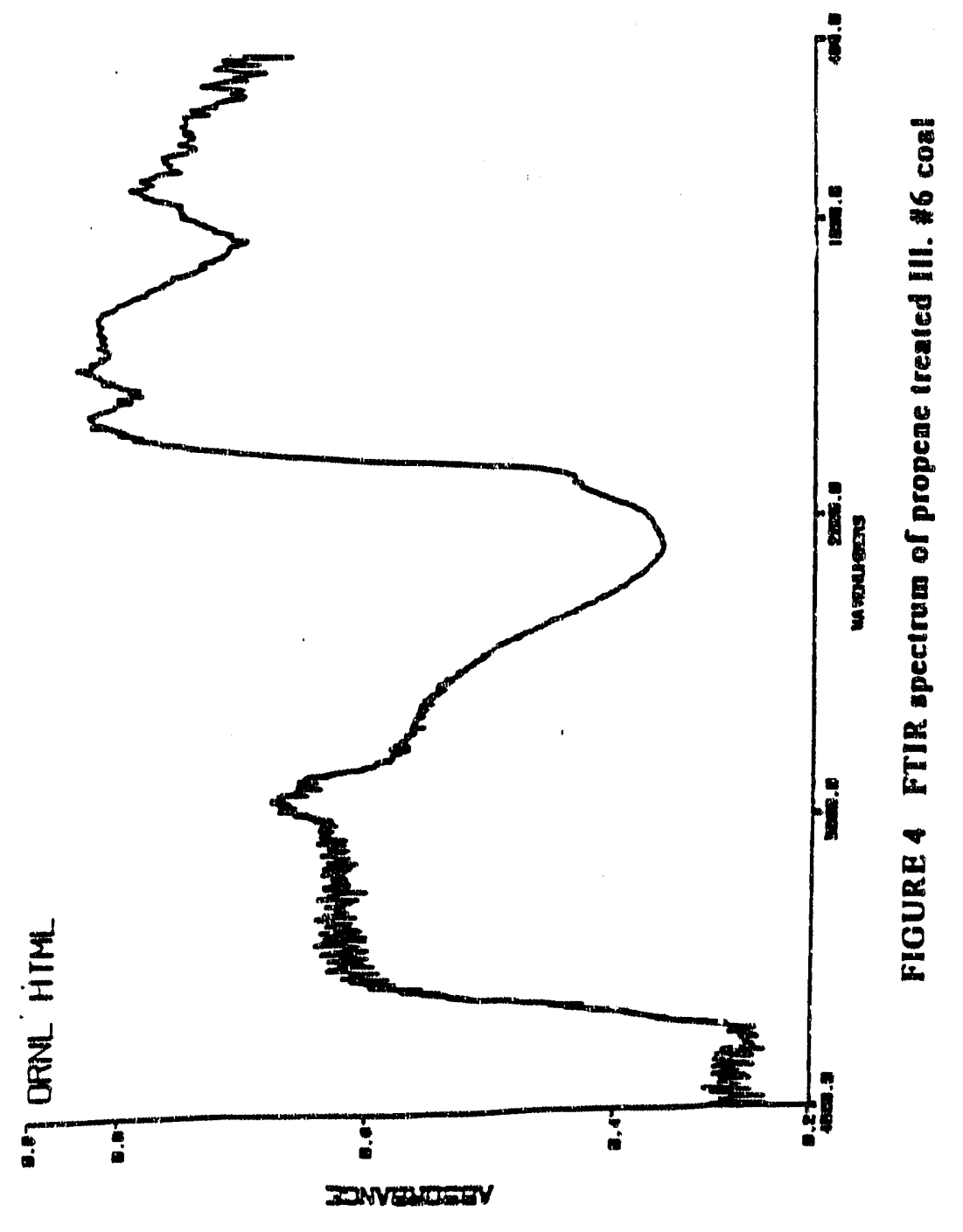




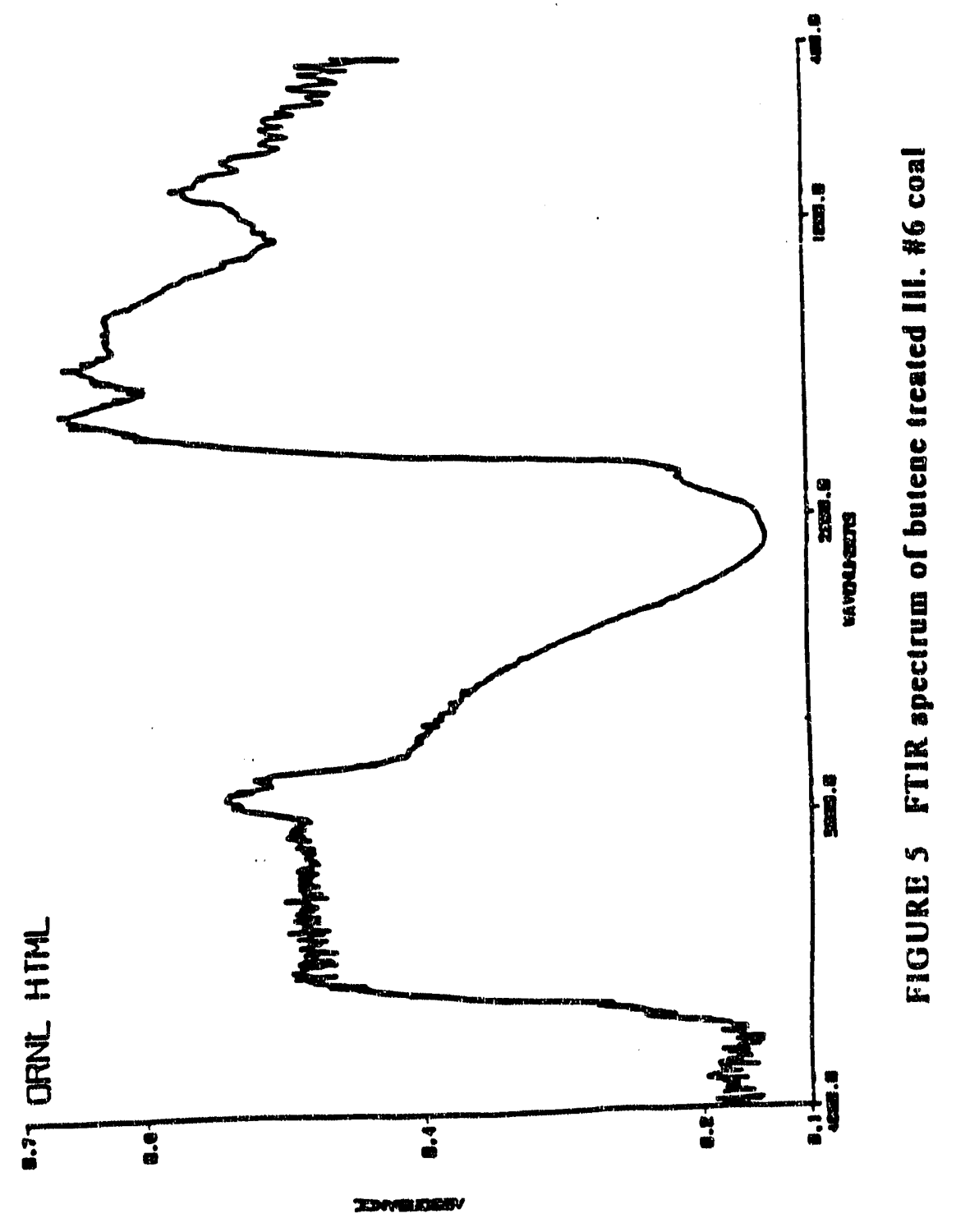




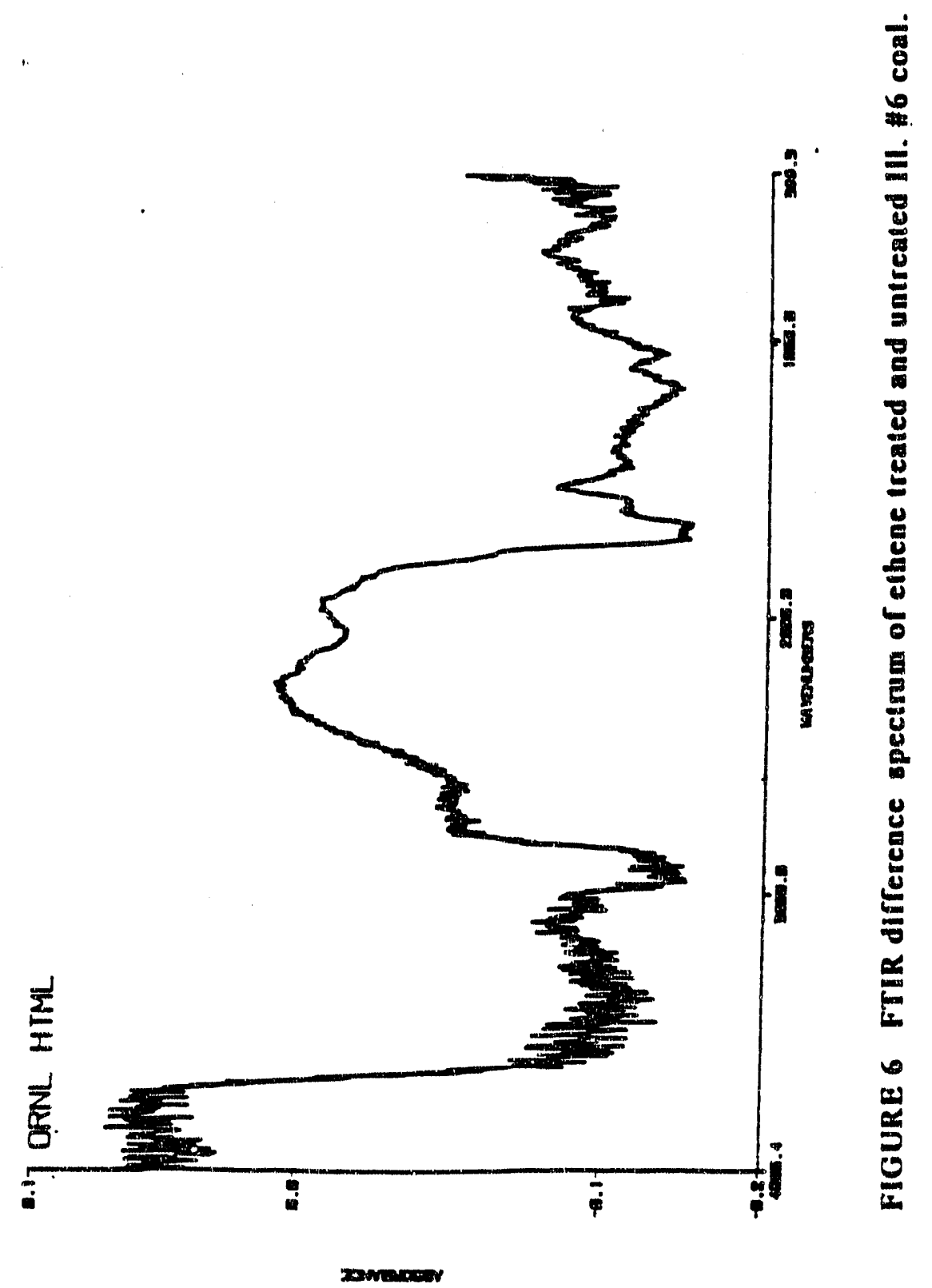




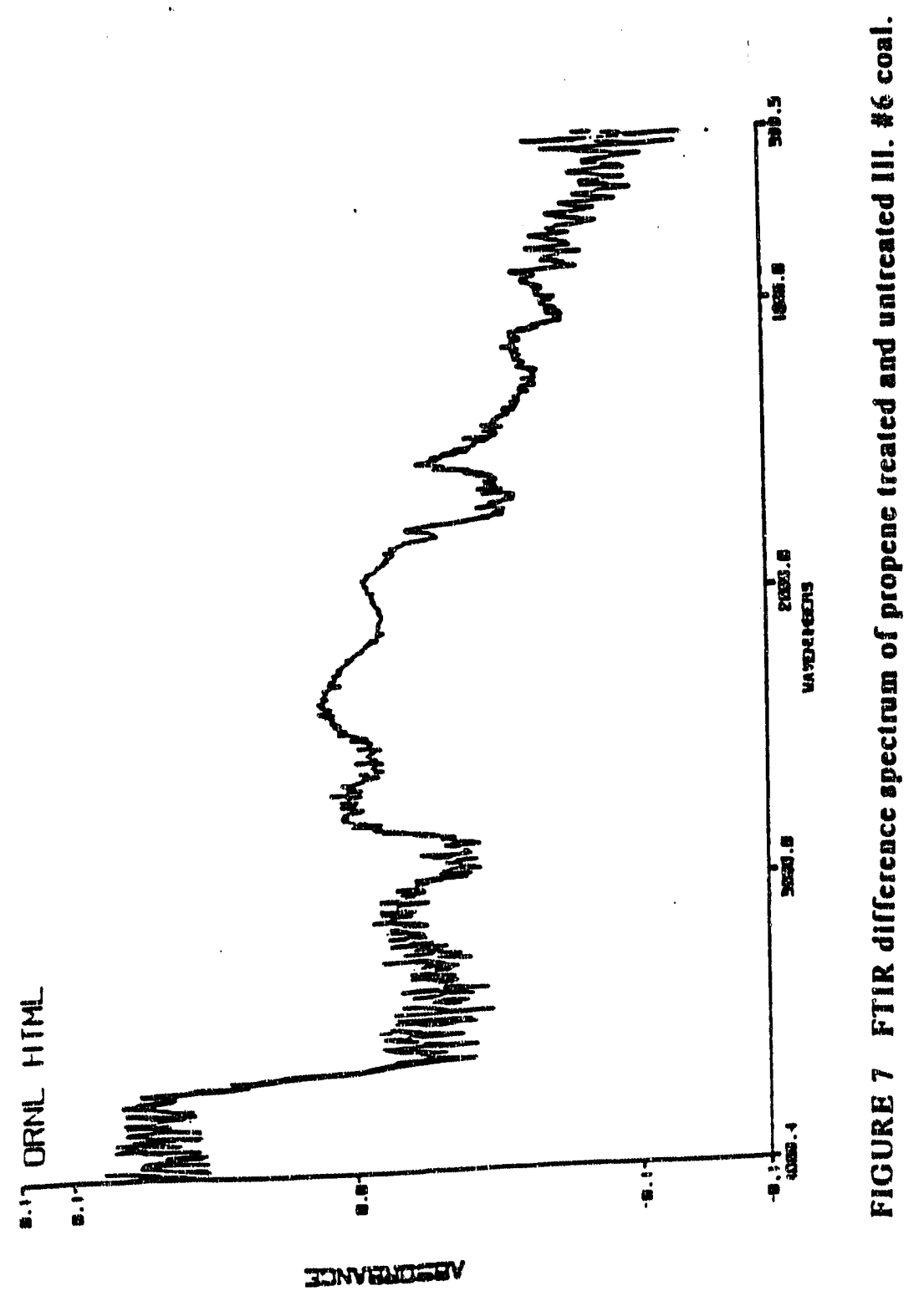




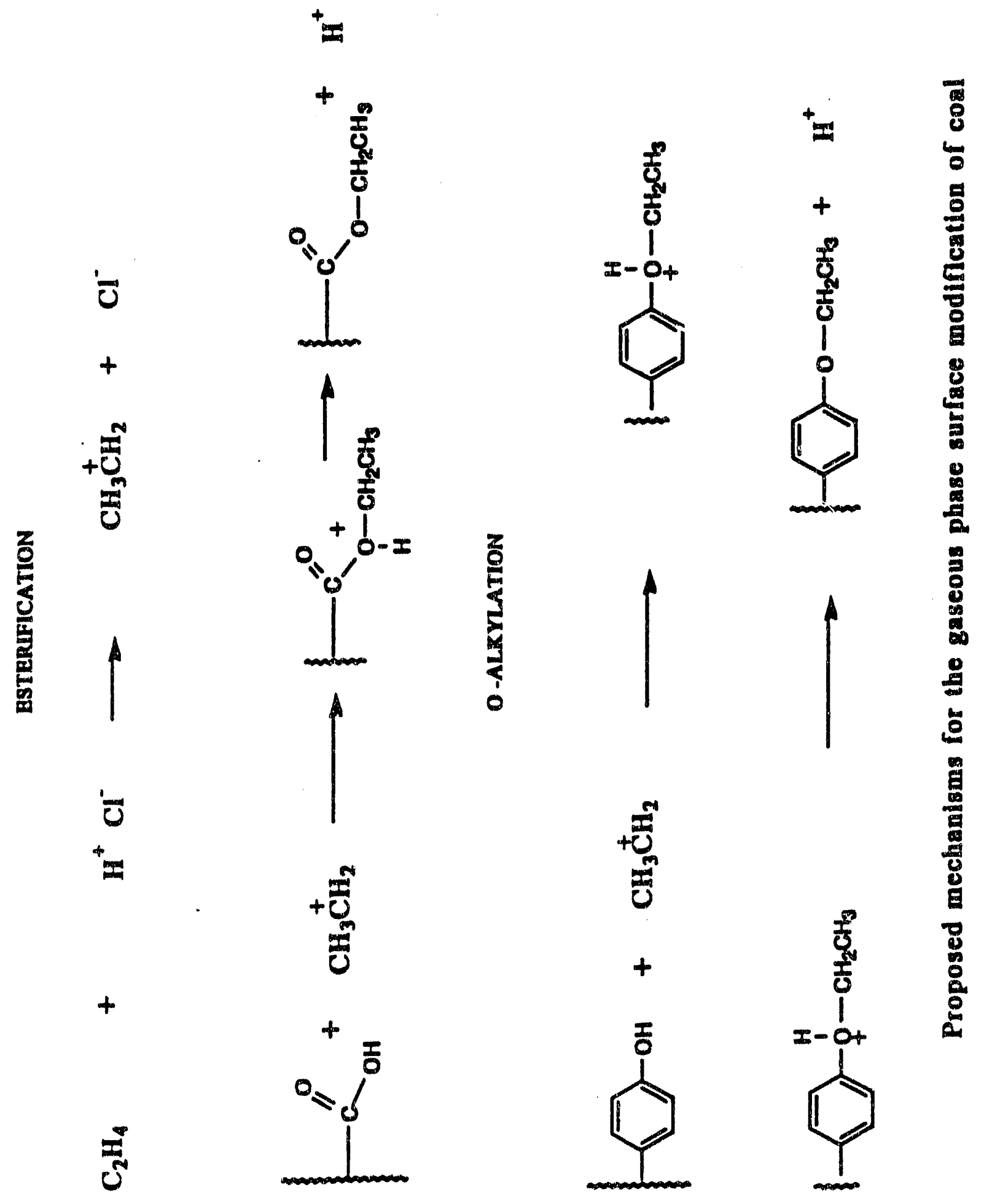




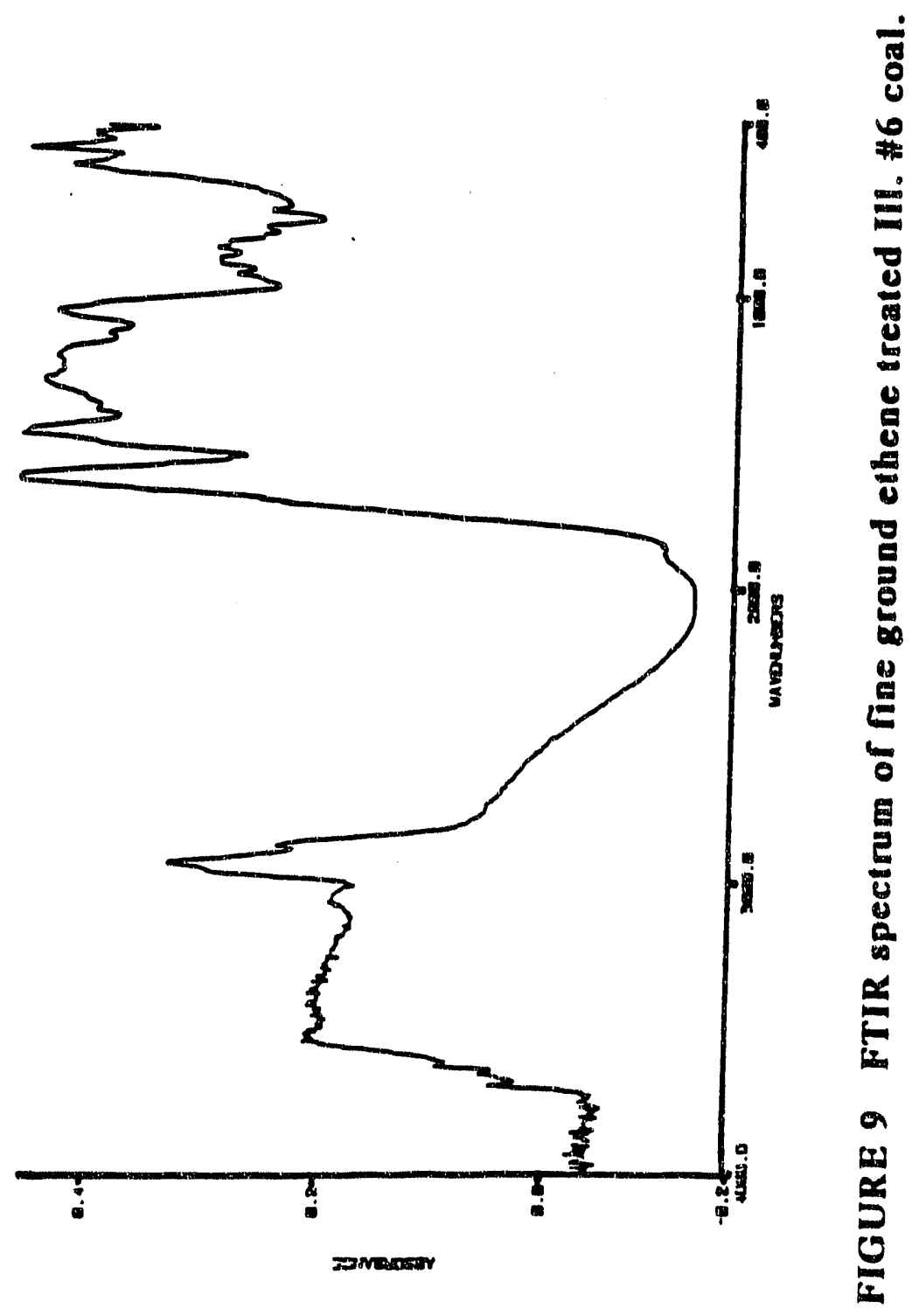




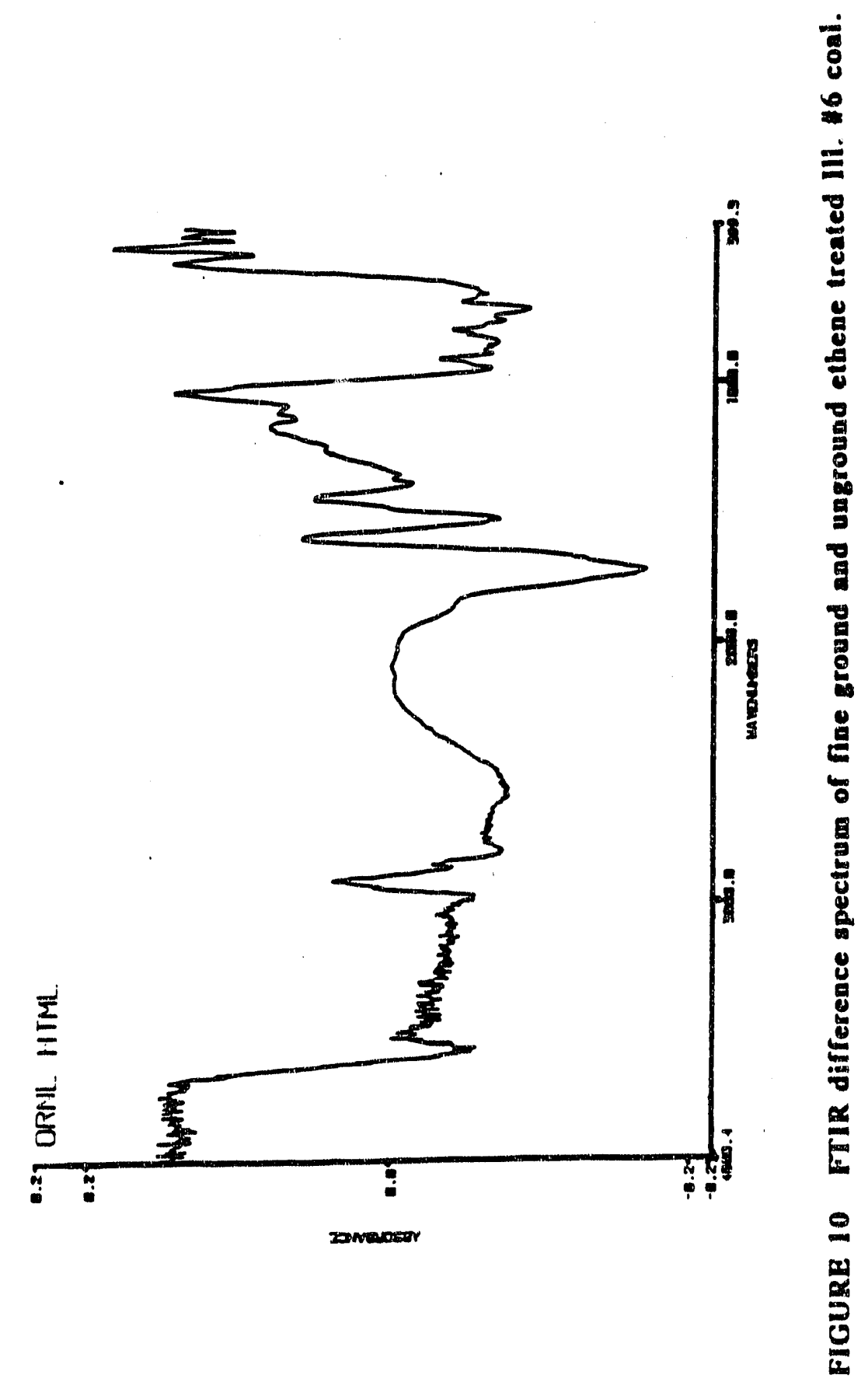




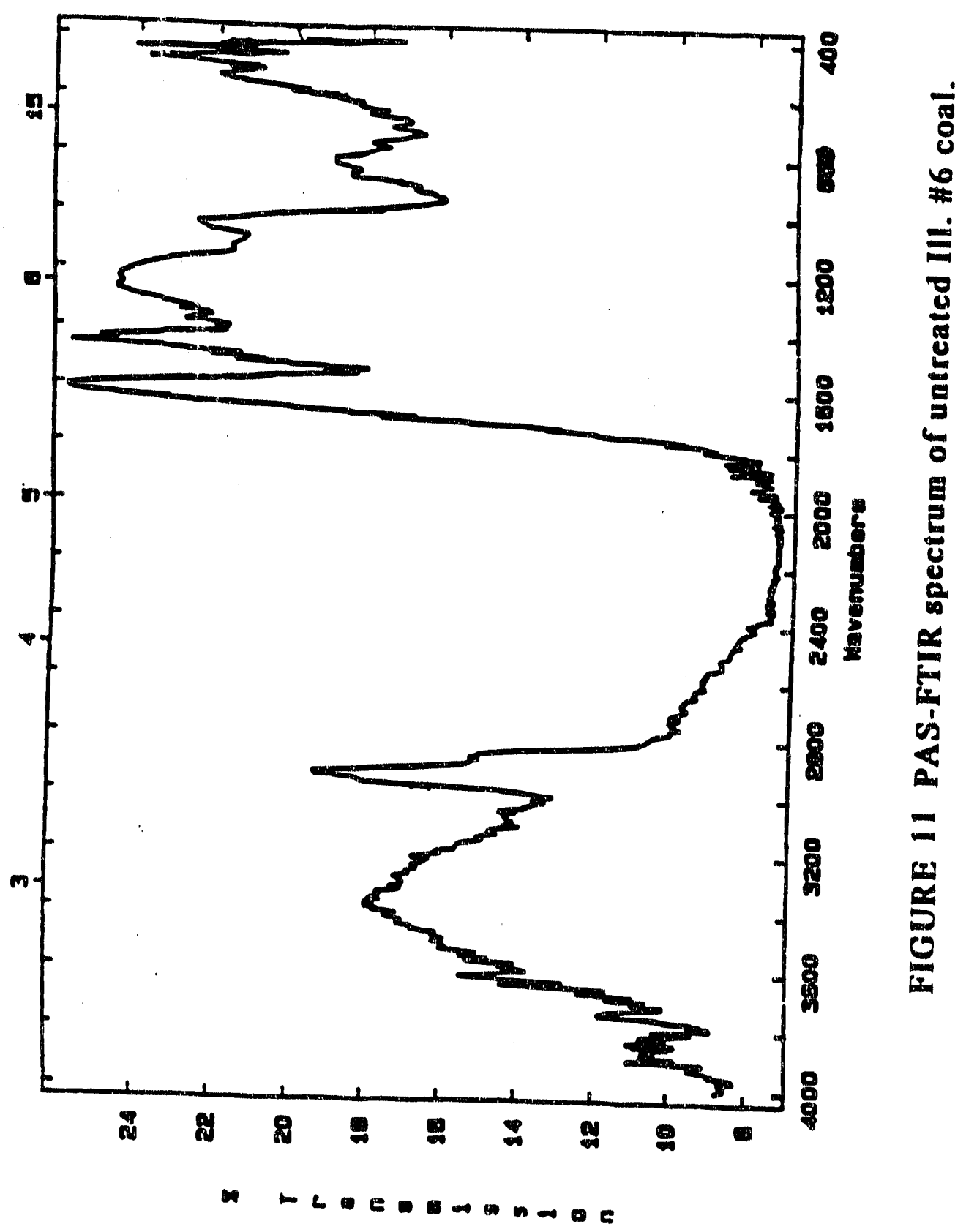




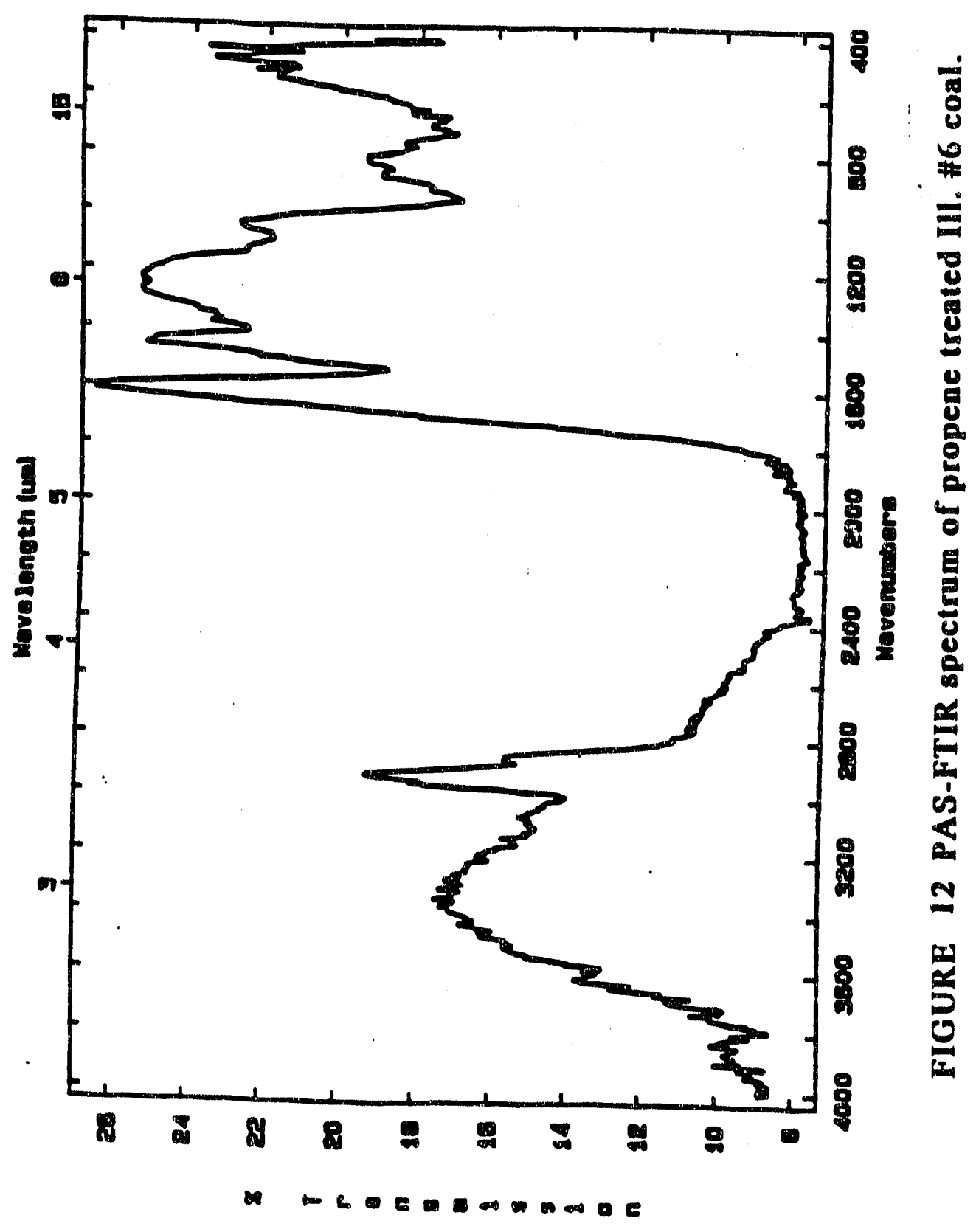




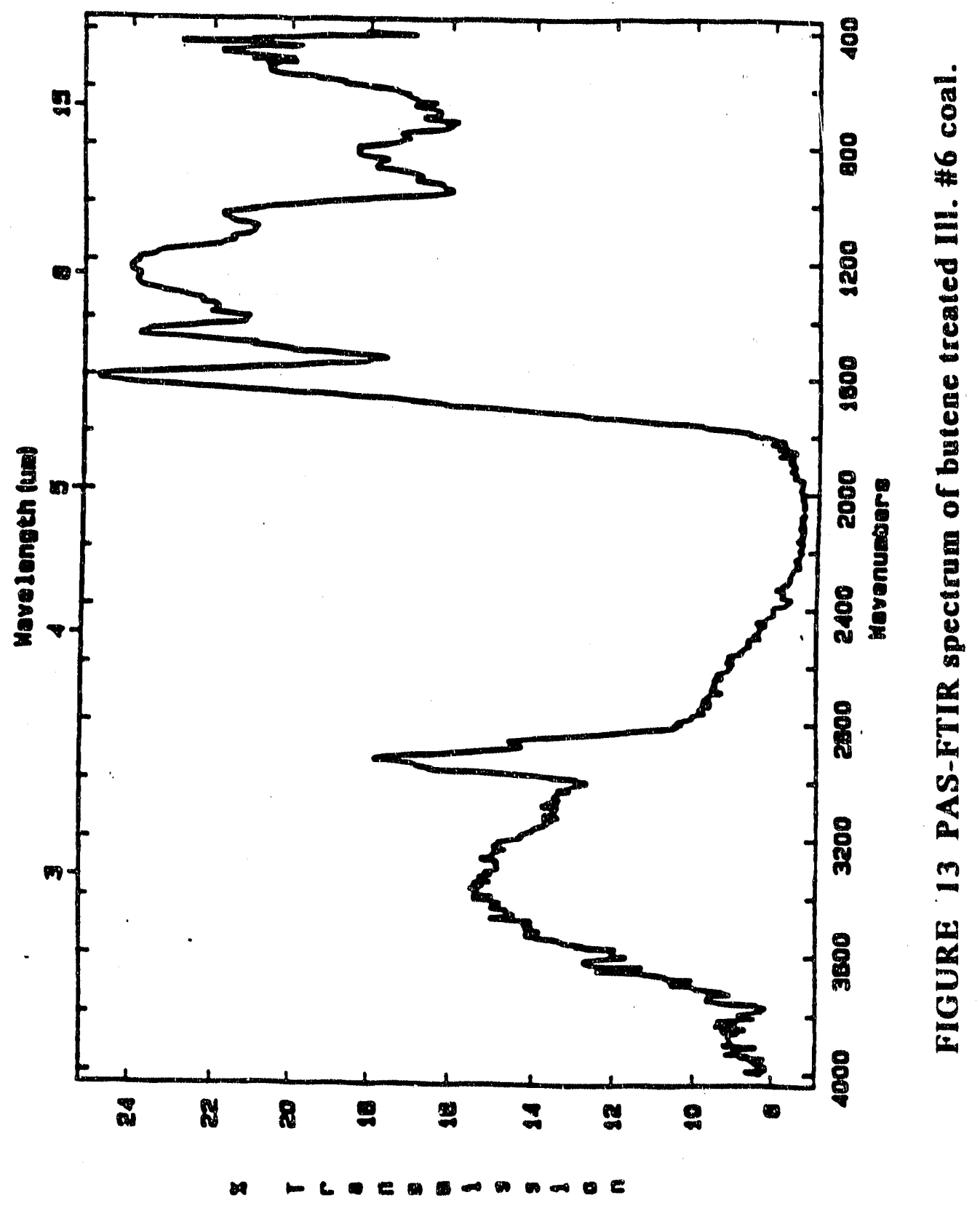




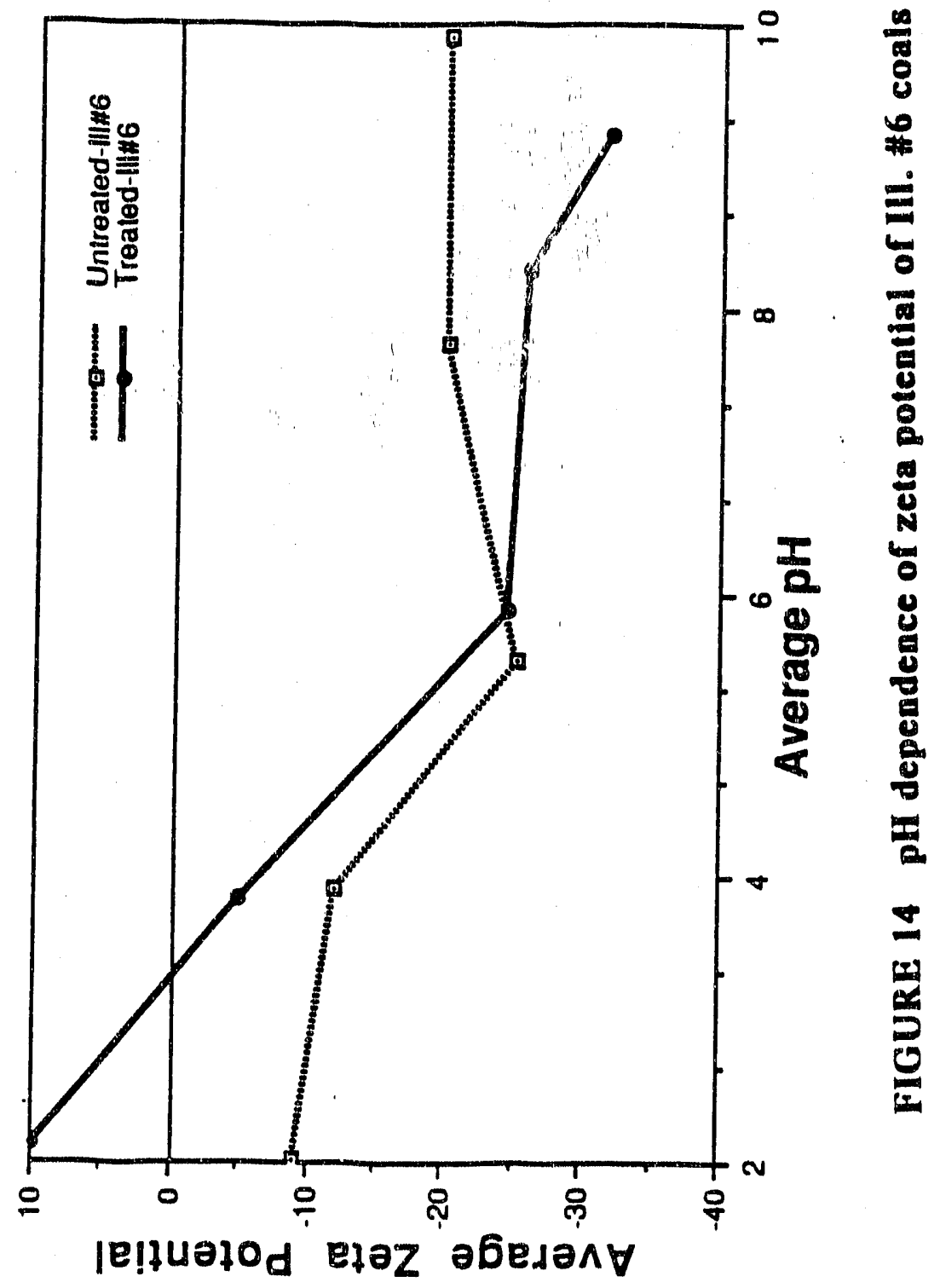




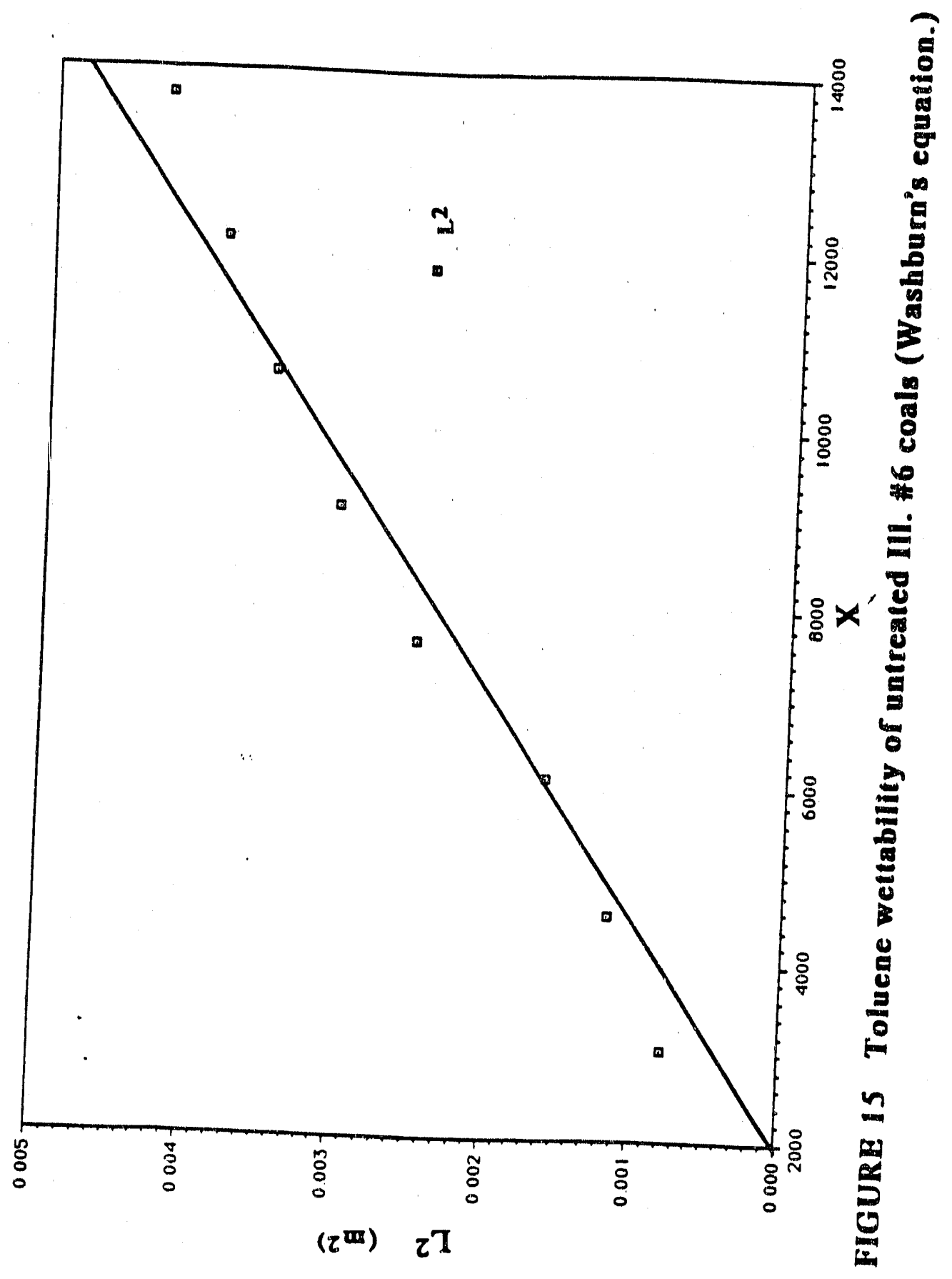




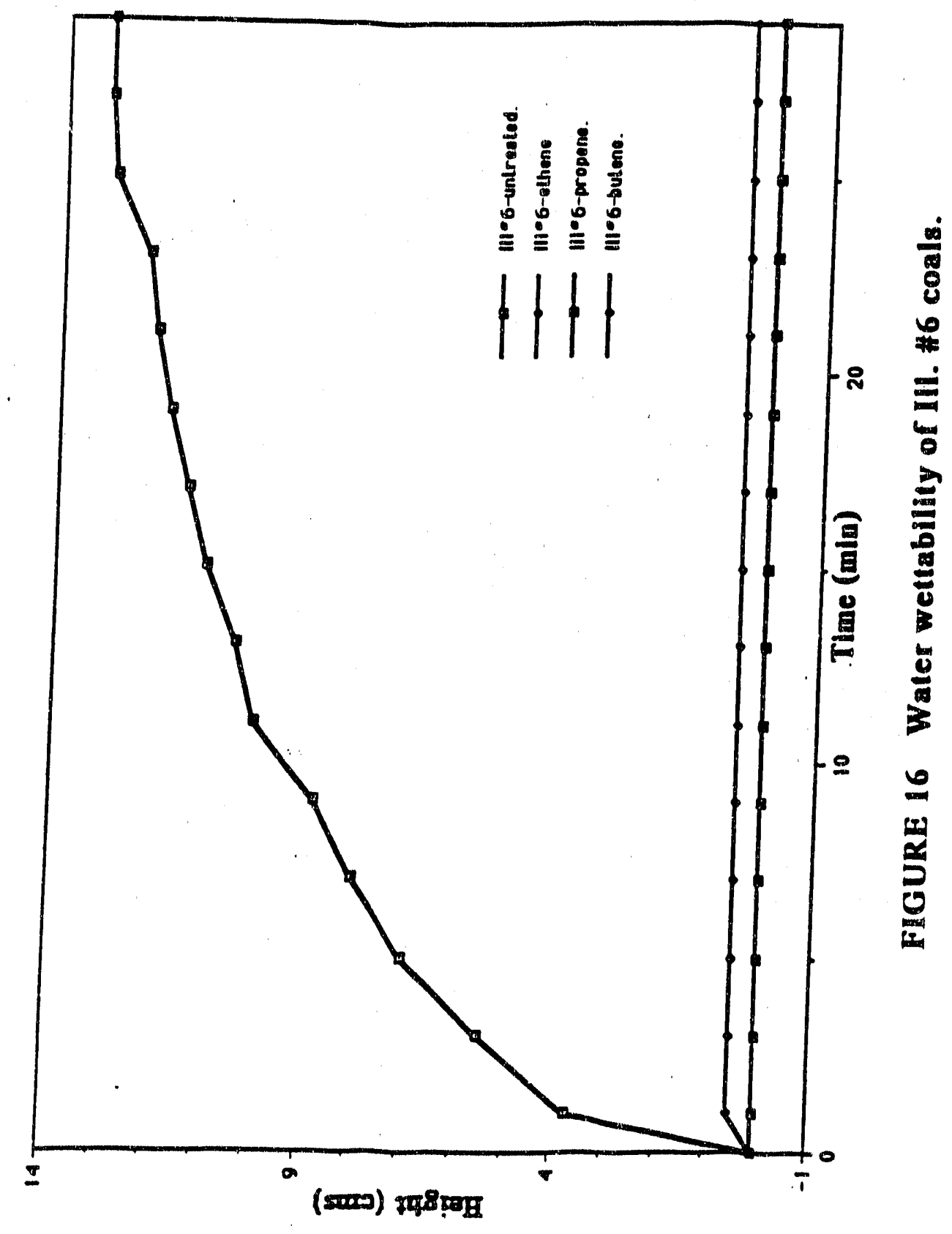




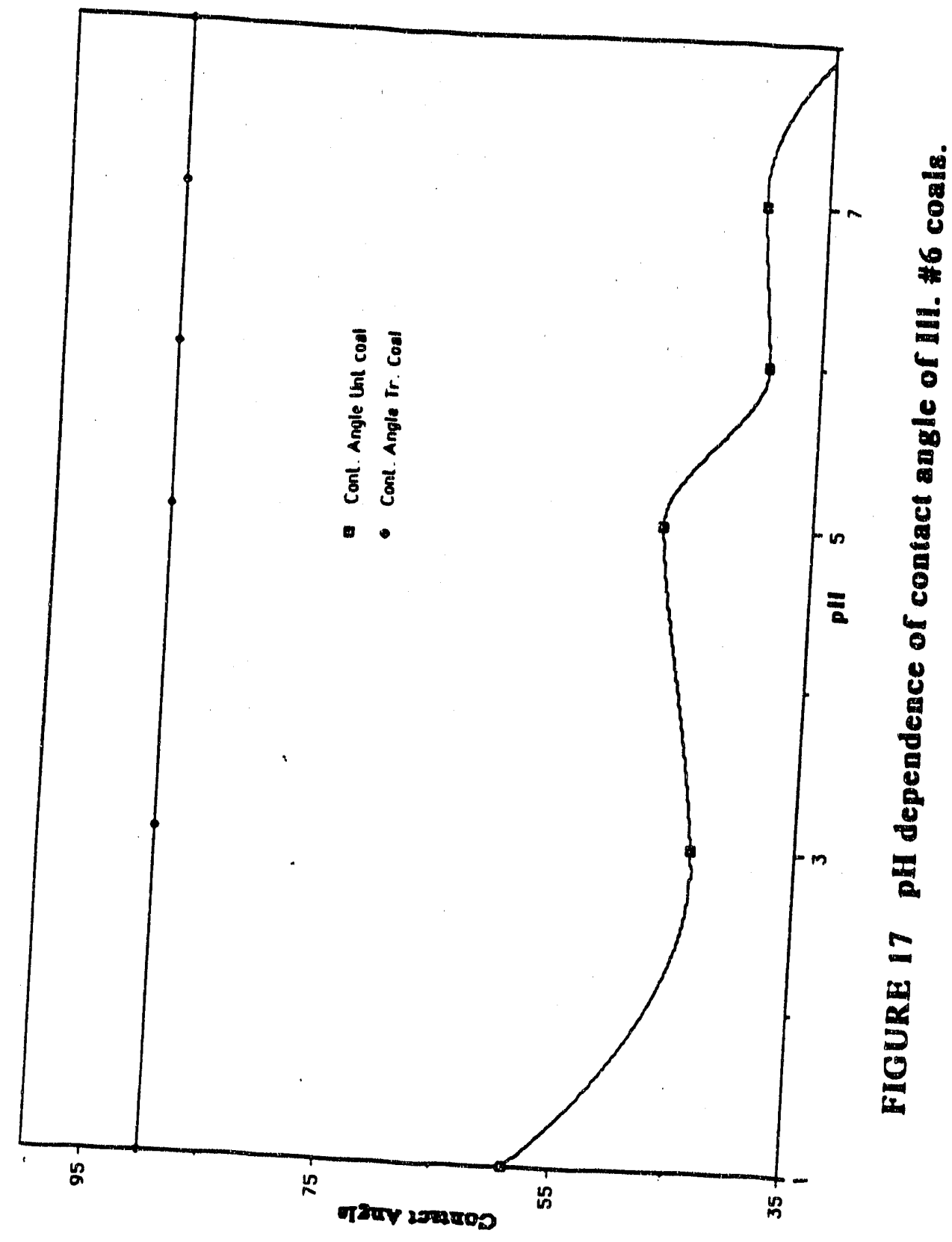




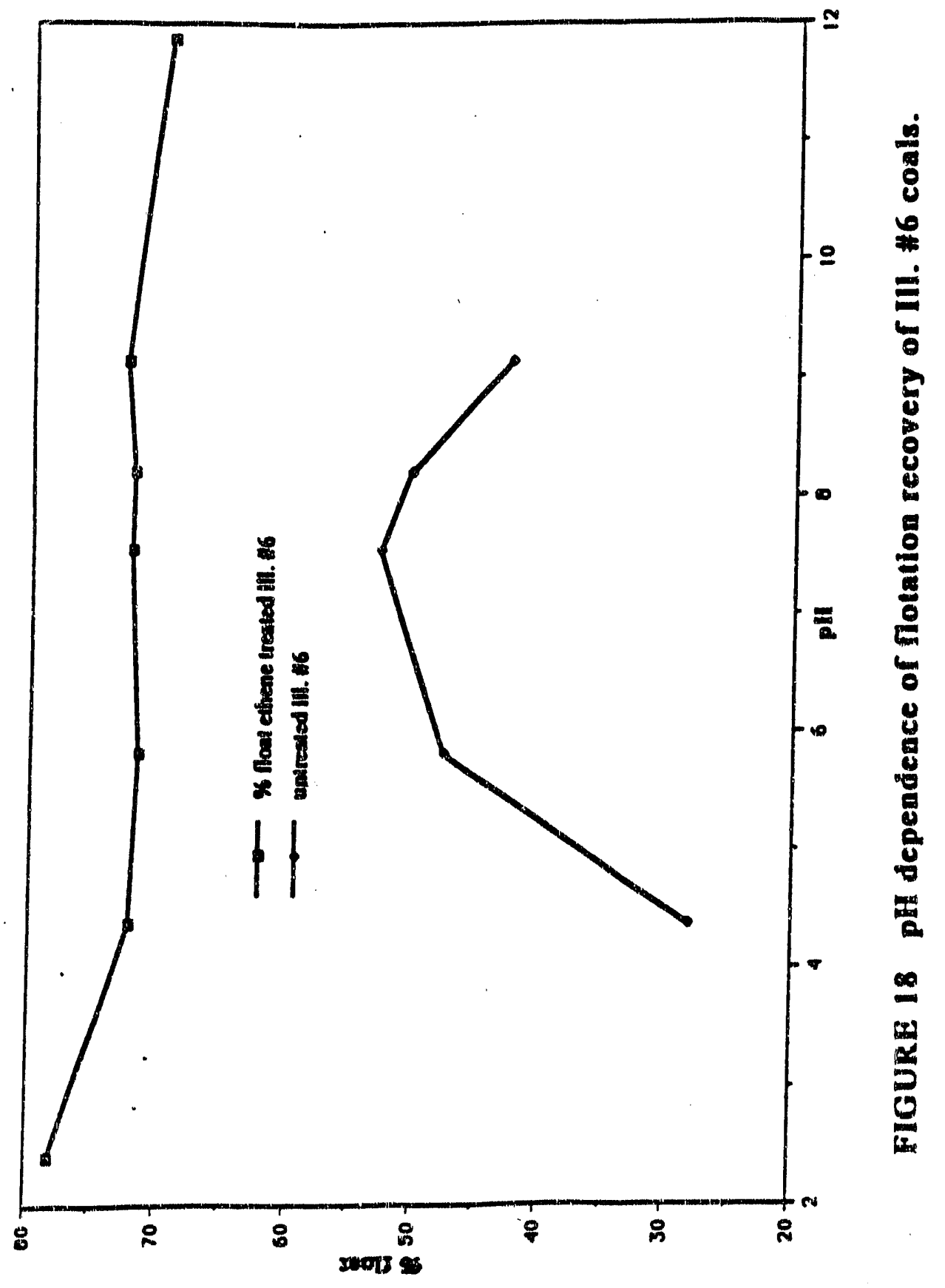




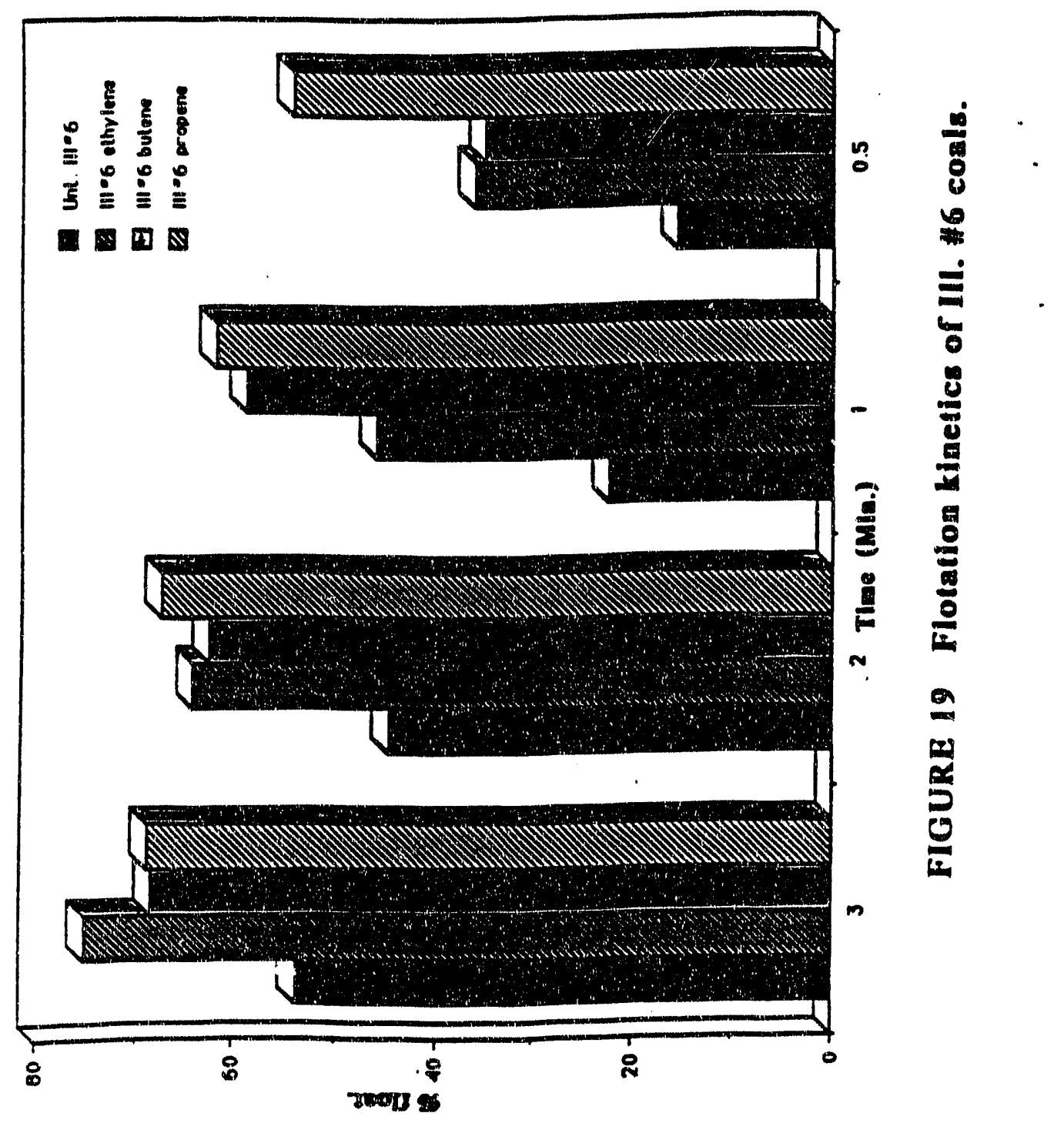



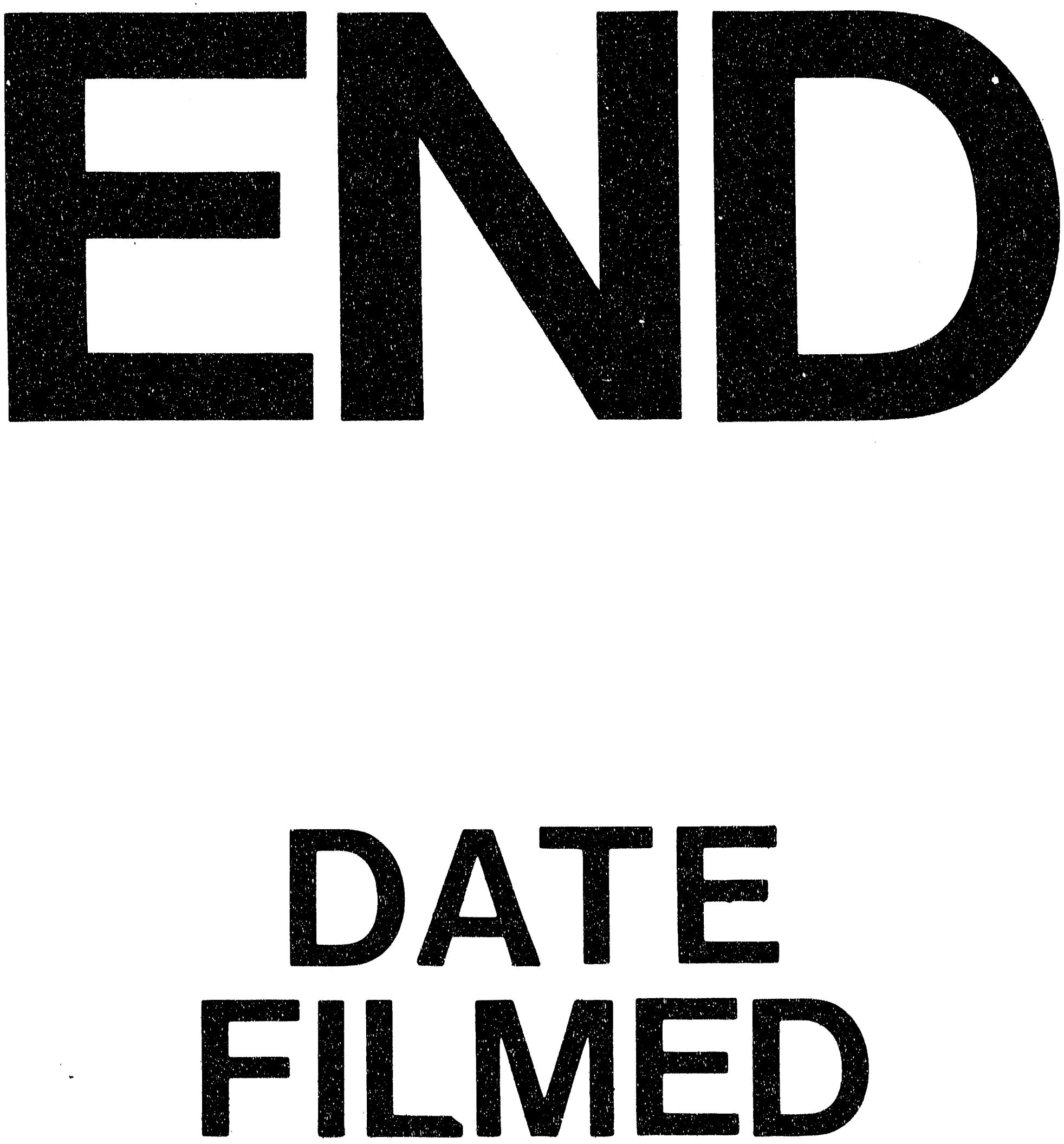

1

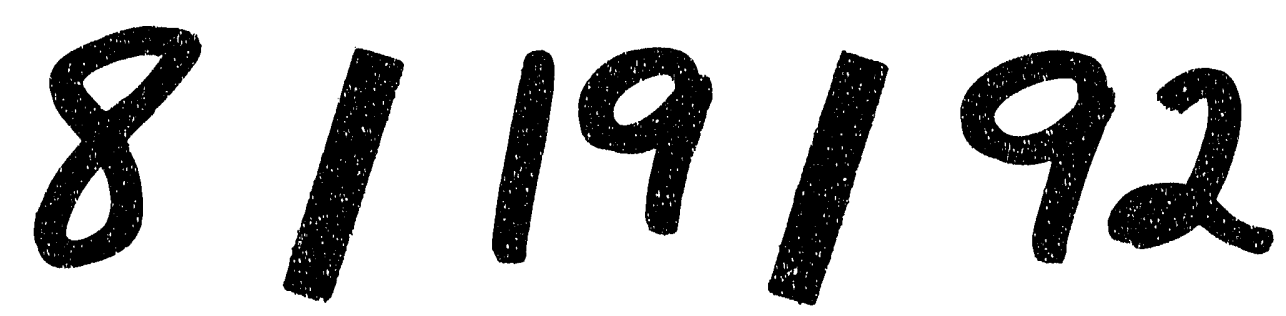


